\title{
The Greenland Gravitational Constant Experiment
}

\author{
MARK A. ZUMBerge, ${ }^{1}$ MARK E. ANDER, ${ }^{2}$ \\ Ted V. Lautzenhiser,${ }^{3}$ ROBert L. Parker, ${ }^{1}$ CARlos L. V. Aiken, ${ }^{4}$ \\ Michael R. Gorman, ${ }^{5}$ Michael Martin Nieto, ${ }^{2}$ A. PAul R. COOPER, ${ }^{5}$ JOHN F. Ferguson, ${ }^{4}$ \\ Eldzabeth Fisher, ${ }^{4}$ James Greer,${ }^{6}$ Phil Hammer, ${ }^{1}$ B. Lyle Hansen, ${ }^{7}$ GeORge A. MCMechan. ${ }^{4}$ \\ GlenN S. SasagaWa, ${ }^{1}$ Cyndi Sidles, ${ }^{4}$ J. Mark STEVenson, ${ }^{1}$ AND Jim WiRTZ ${ }^{3}$
}

\begin{abstract}
An Airy-type geophysical experiment was conducted in a 2-km-deep hole in the Greenland ice cap at depths between $213 \mathrm{~m}$ and $1673 \mathrm{~m}$ to test for possible violations of Newton's inverse square law. The experiment was done at Dye 3, the location of a Distant Early Warning Line radar dome and the site of the deepest of the Greenland Ice-Sheet Program (GISP) drill holes. Gravity measurements were made at eight depths in 183-m intervals with a LaCoste \& Romberg borehole gravity meter. Prior to the experiment the borehole gravity meter was calibrated with an absolute gravity meter, and the wireline depth-finding system used in the borehole logging was calibrated in a vertical mine-shaft against a laser geodimeter. The density of the ice in the region was calculated from measurements taken from ice cores obtained from earlier drilling observations. Ice penetrating radar was employed in order to correct the gravity data for the topography of the ice-rock interface. Surface gravity observations were made to assess the extent to which density variations in the sub-ice rock could affect the vertical gravity gradient. The locations of the gravity observation points were determined with a combination of GPS recording, first-order leveling, and EDM surveying. An anomalous variation in gravity totaling $3.87 \mathrm{mGal}\left(3.87 \times 10^{-5} \mathrm{~m} / \mathrm{s}^{2}\right)$ in a depth interval of $1460 \mathrm{~m}$ was observed. This may be attributed either to a breakdown of Newtonian gravity or to unexpected density variations in the rock below the ice.
\end{abstract}

\section{INTRODUCTION}

Over the three centuries since Isaac Newton authored his Principia a great deal of effort has been devoted to assessing the need for modifications to Newton's inverse square law of gravity [Gillies, 1987]. Investigations during the present decade have been motivated by observations of an anomalous gradient in the Earth's gravity in Australian mines [Stacey and Tuck, 1981; Stacey et al., 1981, 1987; Holding et al., 1986]. The principle of those experiments and the one described here was first employed by Airy [1856].

Experiments of the eighteenth and early nineteenth centuries (including that of Cavendish) were not designed to measure "Newton's constant," $G$; rather, they were attempts to determine the mean density of the Earth [Clotfelter, 1987]. In modern notation, the Newtonian gravitational force $F$ given by

$$
F(r)=G m_{1} m_{2} / r^{2}
$$

is the attraction between point masses $m_{1,2}$ separated by $r$. The variation of the Earth's gravity $g$ with depth in a mine referenced to a point at the Earth's surface is given by

\footnotetext{
${ }^{1}$ Institute of Geophysics and Planetary Physics, Scripps Institution of Oceanography, University of California, San Diego, La Jolla, California.

${ }^{2}$ Los Alamos National Laboratory, University of California, Los Alamos, New Mexico

${ }^{3}$ Amoco Production Company, Tulsa, Oklahoma.

${ }^{4}$ Center for Lithospheric Studies, University of Texas at Dallas. Richardson, Texas.

${ }^{5}$ Scott Polar Research Institute, University of Cambridge, Cambridge, United Kingdom.

${ }^{6}$ UNAVCO, CIRES, University of Colorado, Boulder, Colorado.

${ }^{7}$ PICO, University of Nebraska, Lincoln, Nebraska.

Copyright 1990 by the American Geophysical Union.

Paper number $90 \mathrm{JB} 00792$.

0148-0227/90/90JB-00792\$05.00
}

$$
\Delta g \equiv g(z)-g(0)=(\gamma-4 \pi G \rho) z
$$

where $p$ is the density of the matter surrounding the mine, $z$ is depth, and $\gamma$ is the local free-air gradient of gravity. (This approximation overlooks certain important details discussed below but is adequate for the present discussion.) Thus in an Airy experiment, $G$ can be found by determining $g(z), \rho$, and $\gamma$; essentially it is the attraction of the horizontal slab of material traversed by the $g$ profile that, when separated from the normal vertical gradient of gravity, allows $G$ to be computed.

In his original work, Airy calculated the ratio $g(0) / g(z)$, thereby eliminating $G$ from the calculation. His conclusion was that the Earth's mean density was $6.566 \pm 0.018 \mathrm{~g} / \mathrm{cm}^{2}$. It was only later in the century that attention turned towards the value of what we now call $G$.

Theoretical reasons for suspecting a need to modify Newton's law have been put forth by a number of authors including $F$ ujii [1971] and Goldman et al. [1986]. They predict that there may be new components to gravity, which could violate Newtonian theory through the inverse square law (composition independent), the principle of equivalence (composition dependent), or both.

The value of $G$ calculated by the Australian group exceeded by nearly $1 \%$ the value measured in laboratory experiments [e.g., Luther and Towler, 1982; Pontikis, 1972]. This was the first modern evidence for a possible breakdown of the inverse square law. The notion of a breakdown in Newton's law gained support after a re-analysis of the well-known Eötvös experiment by Fischbach et al. [1986], where a striking correlation between composition and an apparent gravity-like force was demonstrated in a number of materials.

Since those two works (the Australian mine experiment and the Eötvös reanalysis), a flurry of investigations has been initiated in geophysical and laboratory settings. In addition to the experiment described here (and in part by Ander et al. [1989]), major efforts have been made by Eckhardt et al. [1988], Adelberger et al. [1987], Thieberger [1987], Stubbs et al. [1987], 
Thomas et al. [1989], and Boynton et al. [1987]. Most of the observations reported as evidence for a breakdown of Newtonian theory have since been explained with conventional physics [Bartlett and Ten', 1989; Jekeli et al., 1989; Parker and Zumberge, 1989; also G. Tuck, private communication, 1989]. The current situation can be fairly summarized with the mild statement that if Newton's law requires modification, the details, including sign, are not well determined.

Our collaboration was assembled from a group formed to design an Airy experiment in the ocean, where a large number of advantages exist for accurately determining $\gamma$ and especially $\rho$, and where technology exists for making measurements of $g(z)$ over a broad range of $z$ [Hildebrand et al., 1988]. However, gravity measurements in a medium undergoing constant motion present difficulties not easily circumvented. With the realization that the polar ice sheets are in many respects frozen oceans, we turned our attention to performing an Airy experiment in ice, where $g(z)$ could be much more easily measured.
We chose a borehole located at Dye 3, Greenland, for the experiment for several reasons, including (1) the borehole through the ice there is one of the world's deepest $(2037 \mathrm{~m}$ to bedrock); (2) a significant amount of geophysical data had already been collected there; and (3) the logistical support allowed rapid deployment.

As stated in the discussion below, the conclusion from the Greenland project is interesting but, unfortunately, not definitive. The methods employed in the experiment, however, have served to allow us to design better experiments in the future (including one in progress in the ocean [Hildebrand et al., 1988] and one planned for Antarctica) and to evaluate other experiments already reported [Parker and Zumberge, 1989].

\section{OVERVIEW OF THE EXPERIMENT}

A major accomplishment of the Greenland Ice Sheet Program was the completion in 1981 of a 2037-m deep hole drilled

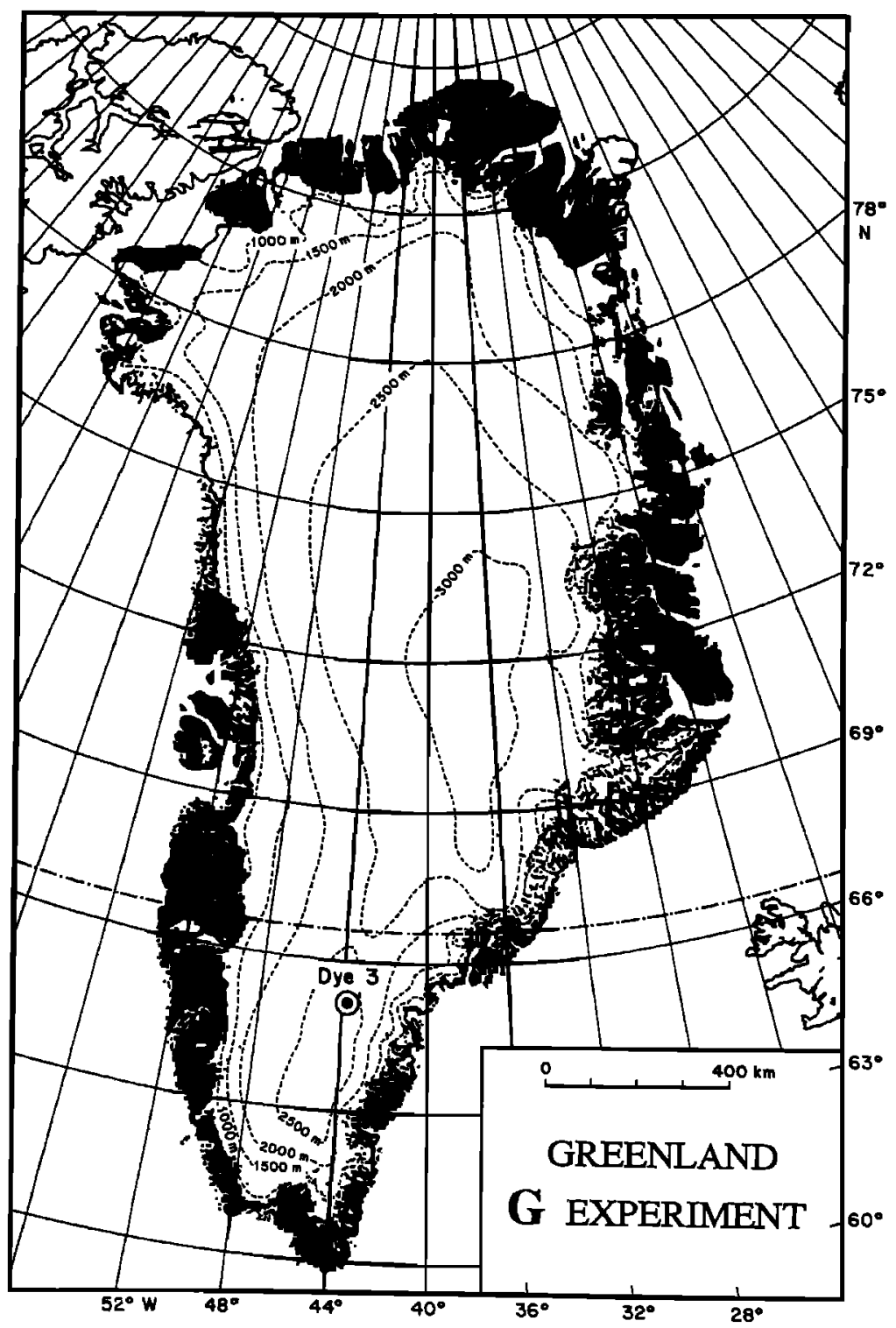

Fig. 1. Map of Greenland. Dye 3 is a Distant Early Warning line (DEW line) station atop a 2-km-thick ice sheet. The contour lines indicate the altitude of the ice surface in meters. 
through the ice cap to bedrock in southem Greenland [Langway et al., 1985]. The borehole is situated near a Distant Early Warning (DEW) line station called Dye 3 that was built in the early 1960's (Figure 1). The primary motivation for the hole was to obtain deep ice cores for glaciological and climate studies. Aside from a gentle slope of $2 \mathrm{~m}$ per kilometer, the terrain on the surface of the ice sheet is quite flat; surface undulations are on the order of $10 \mathrm{~m}$ in amplitude and have kilometer-scale wavelengths over a region of hundreds of kilometers. The sub-ice terrain, on the other hand, is fairly rugged.

The 12.7-cm-diameter borehole was drilled with an electromechanical coring drill [Gundestrup and Johnsen, 1985] and backfilled with an antifreeze fluid mixture of diesel fuel and perchlorethylene to prevent its collapse under the ice overburden. Temperature in the hole varies from $-21^{\circ} \mathrm{C}$ near the surface to $-13^{\circ} \mathrm{C}$ at the bottom, and the inclination varies from near vertical to about $10^{\circ}$ from vertical near the bottom [Gundestrup and Hansen, 1984].

The scenario for this experiment, illustrated in Figure 2, requires determining four quantities: (1) values of the Earth's gravity in the ice borehole; (2) the depths at which those measurements are made; (3) the density of the ice as a function of depth; and (4) the gravity field due to sources other than the slab of ice through which the gravity profile is made.

\section{Dye 3, Greenland}

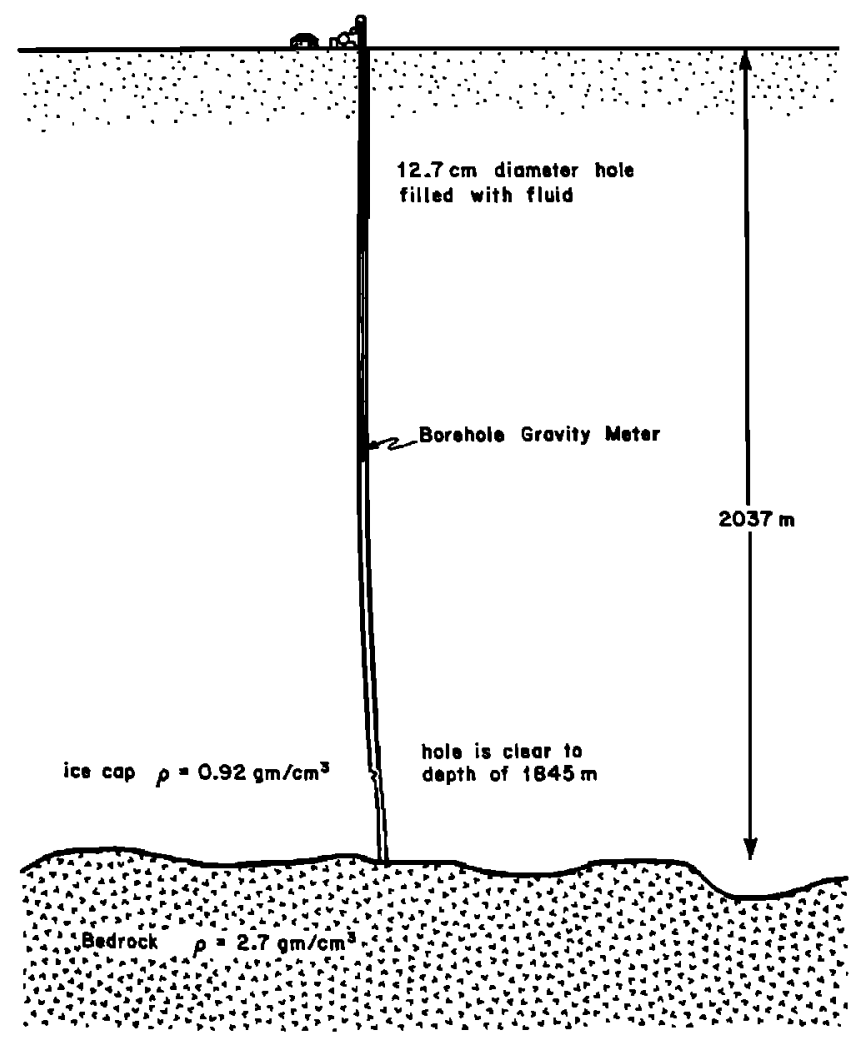

Fig. 2. Cross section of the ice sheet. The borehole is filled with a mixture of perchlorethylene and diesel fuel to prevent its closure. At the depth corresponding to the Holocene-Wisconsin boundary, a mechanical discontinuity occurs and results in deformation of the borehole. In the upper $100 \mathrm{~m}$ the snow gradually is compressed into fim and then ice containing trapped air bubbles.

\section{A SiMPLIFIED MODEL}

For the purpose of simplifying this discussion, consider a flat slab of ice, having uniform density, and infinite horizontal extent overlying a spherical Earth. Two effects determine the difference in gravity, $g$, between points on either side of the slab. The first is the Earth's free-air gravity gradient and the second is the attraction from the slab itself. These terms combine to yield a gravity difference

$$
\begin{aligned}
g_{\text {top }}-g_{\text {bottom }} & =\{2 \pi G \rho \Delta z\}-\{\gamma \Delta z-2 \pi G \rho \Delta z\} \\
& =\left\{\begin{array}{c}
\text { attraction } \\
\text { of slab }
\end{array}\right\}-\left\{\begin{array}{c}
\text { gradient effect } \\
- \text { attraction of slab }
\end{array}\right\}
\end{aligned}
$$

where $\gamma$ is the Earth's free-air gravity gradient $(=3.09 \mu \mathrm{Gal} / \mathrm{cm}$ ) and $\rho$ is the ice density (which is very close to $0.917 \mathrm{~g} / \mathrm{cm}^{3}$ throughout most of the ice sheet; see below). Acquiring the gravity profile over an interval $\Delta z$ of $1500 \mathrm{~m}$ (the ice density is less well known in the first few hundred meters) would give the approximate difference

$$
\begin{aligned}
g_{\text {top }}-g_{\text {bottom }} & =4 \pi G \rho \Delta z-\gamma \Delta z \\
& =116 \mathrm{mGal}-464 \mathrm{mGal}=-348 \mathrm{mGal}
\end{aligned}
$$

Most of the observed gravity increase with depth is due to the free-air gradient. The signal from which $G$ can be extracted is only that portion of the gravity change due to the ice. To obtain a fractional uncertainty of $\varepsilon=10^{-3}$ in the calculation of $G$, one needs to measure $\Delta g$ with an accuracy of $\varepsilon \times 116 \mathrm{mGal}$ $=116 \mu \mathrm{Gal}$. Because the in situ gravity gradient is $\approx 2.2$ $\mu \mathrm{Gal} / \mathrm{cm}$, the relative depth of the gravity meter is needed to an accuracy of $116 \mu \mathrm{Gal} / 2.2 \mu \mathrm{Gal} / \mathrm{cm}$, or $52 \mathrm{~cm}$. The non-free-air portion of the gravity gradient depends directly on the ice density, so $\rho_{\text {ice }}$ must be known to $\varepsilon \rho$, or roughly $0.001 \mathrm{~g} / \mathrm{cm}^{3}$. Finally, the gravity gradient from sub-ice topography must be calculated to an accuracy of $116 \mu \mathrm{Gal} / 1500 \mathrm{~m}=0.0008$ $\mu \mathrm{Gal} / \mathrm{cm}$.

\section{INSTRUMENT CALIBRATIONS}

\section{The Borehole Gravity Meter}

We calibrated the borehole gravity meter (BHGM) before the survey of the ice borehole. The meter used was Amoco Production Company's LaCoste \& Romberg BHGM \#14, the first "slimhole" gravity meter having worldwide range without requiring reset (that is, its dynamic range exceeds the total gravity variation over the globe). Calibration was conducted over a gravity range in Canada and Alaska, designed to span 338 $\mathrm{mGal}$, the expected range of gravity values down the length of the Dye 3 borehole. We set $50 \mu \mathrm{Gal}$ as an acceptable limit on the error due to imperfect calibration, contributing 4 parts in $10^{4}$ to the error in $G(50 \mu \mathrm{Gal} / 116 \mathrm{mGal})$; this requires that the BHGM's calibration factor be known to $\pm 1.5 \times 10^{-4}$. Other sources of imperfection, like circular error in the BHGM's measuring screw, are negligible at this level. We only need to know the multiplicative factor which, if ignored, can contribute an error of several tenths of a milligal over the range of gravity we encountered in Greenland.

A calibration range was set up with an absolute gravity meter several months before the Greenland survey. The range consisted of two sites separated by about $200 \mathrm{mGal}$ and a 2-hour drive. The BHGM was repeatedly read at the absolute sites that provided a known gravity interval. 
The value of gravity at the surface of the Dye 3 borehole is approximately $981,600 \mathrm{mGal}$ [Jezek et al., 1985]. Absolute gravity values obtained for the calibration spanned 171.841 $\mathrm{mGal}$, ranging from $981,660.579 \mathrm{mGal}$ (at the Blanchard River Maintenance (BRM) Station in Canada) to $981,832.420 \mathrm{mGal}$ (at the Haines Fairground in Alaska (HFG)). The range was extended to a higher elevation with relative gravity meters calibrated elsewhere to give a total calibration interval of 242.27 mGal.

The calibration consisted of two round trips between HFG and BRM with stops at an intermediate location having higher elevation. Between three and five readings of the BHGM were taken at each location at 5-min intervals with 1 -min clamp periods. During transit the meter measuring screw was run to the approximate reading expected at the next location.

The absolute gravity meter produced differential measurements with an accuracy of $14 \mu \mathrm{Gal}$. The BHGM produced differential measurements with a precision of $21 \mu \mathrm{Gal}$. The multiplicative factor calculated to force agreement between the two is $(8.1 \pm 1.5) \times 10^{-4}$.

When applied to the BHGM measurements taken in the Dye 3 borehole, the scale factor correction uncertainty of $1.5 \times 10^{-4}$ leads to an uncertainty of $51 \mu \mathrm{Gal}$. This calibration uncertainty meets the requirement of the Greenland $G$ experiment. Further details of the calibration are given by Sasagawa et al. [1989].

\section{The Wireline}

It was necessary to measure the depth of the gravity meter, attached to a wireline in the ice borehole, to an accuracy of about $50 \mathrm{~cm}$ in $2 \mathrm{~km}$. This required a fractional accuracy of 3 parts in $10^{4}$. In order to be assured of this accuracy, the wireline length measuring system had to be calibrated both before and after the Greenland expedition [Ander et al., 1989]. The calibration was conducted in a $1200-\mathrm{m}$ vertical mine shaft at the Consolidated Silver Mine in Osborn, Idaho. Distances in the mine shaft were first determined to an accuracy of about $1 \mathrm{~cm}$ using a laser geodimeter. Then the actual wireline used in Greenland was lowered into the mine shaft, and the depth found with its system was compared with the depths known from the geodetic survey.

The system which determined the length of the wireline in the borehole was developed by the Kerr Measurement System, Inc., of Houston, Texas, for use in the oil well logging industry. In this system, the wireline, under well-controlled tension, is marked magnetically at accurately determined $30.48-\mathrm{m}$ intervals along its length. During operation in the borehole, the magnetic marks are electronically counted at the winch as the cable is lowered into the hole (tangential wheels with shaft encoders interpolate the wireline length between the magnetic marks), and the tension in the cable is measured by a load cell at the well head. The wireline length is then calculated using the length measured at the surface, the measured cable tension, the temperature profile in the borehole, the fluid density, and the mechanical and thermal properties of the wireline. These properties need not be known with great accuracy because the stretching and thermal expansion amount to only a few meters at the depths of the Dye 3 borehole.

The inelastic stretch is less well controlled. Problems from permanent and unknown deformation in the cable were circumvented by "seasoning" it prior to the calibration by placing a $2270-\mathrm{kg}$ load on the end of the cable and pulling it behind a truck until its Iength no longer changed.
After the Greenland experiment, the first $1829 \mathrm{~m}$ of the wireline were degaussed and new magnetic marks were placed on it. The new mark at $1829 \mathrm{~m}$ was only $0.102 \mathrm{~m}$ short of the old mark. Thus the Greenland operation caused $0.102 \mathrm{~m}$ of new inelastic stretch over $1829 \mathrm{~m}$, producing an insignificant depth measurement error. After the wireline was re-marked we retumed to the Consolidated Silver Mine in late October of 1987 to test the measuring system again. We found that it reproduced the depths determined geodetically to within a few centimeters [Ander et al., 1989].

\section{DENSITY OF ICE}

The material that generates the signal in this experiment is, of course, the ice itself. It is important that the density of the ice be known with high accuracy, since $G$ is directly proportional to it in the calculation.

The physical and chemical properties of ice, fortunately, have been studied extensively by glaciologists. Laboratory experiments have determined the density of pure ice to an accuracy of 5 parts in $10^{5}$ [Hobbs, 1974], and ice samples from both Antarctica [Gow, 1971] and from the Dye 3 station in Greenland have been analyzed in detail [Shoji and Langway, 1985]. Based on these studies we can predict the density of ice as a function of depth with an uncertainty less than 1 part in $10^{3}$.

There are three principal components in the ice density model: pressure, temperature, and air content. Our model includes modification to a slab of pure ice with these effects; other perturbations are negligible. Ignoring the bubbles for a moment, we would expect the density $\rho(z)$ to vary with depth $z$ according to

$$
\rho(z)=\rho(0)\left\{\frac{1+K^{-1} \Delta P(z)}{1+\beta \Delta T(z)}\right\}
$$

where $K$ and $\beta$ are the bulk modulus and volumetric thermal expansion coefficient for the ice and $\Delta P$ and $\Delta T$ are the pressure and temperature relative to atmospheric pressure and $0^{\circ} \mathrm{C}$. Both the numerator and denominator in (5) amount to corrections on the order of $2 \times 10^{-3}$ for the depth of the Dye 3 hole; we therefore only need to know the coefficients to $10 \%$ to get the corrections due to them precise to 2 parts in $10^{4}$.

The details of the ice density calculation are given in Appen$\operatorname{dix}$ A. The results are in Table 1, which contains the predicted density profile below $200 \mathrm{~m}$; the density above this depth has

TABLE 1. Predicted Density

\begin{tabular}{cc}
\hline Depth, $\mathrm{m}$ & Density, $\mathrm{g} \mathrm{cm}^{-3}$ \\
\hline 200 & 0.9141 \\
300 & 0.9163 \\
400 & 0.9173 \\
500 & 0.9179 \\
600 & 0.9184 \\
700 & 0.9187 \\
800 & 0.9190 \\
900 & 0.9192 \\
1000 & 0.9194 \\
1100 & 0.9196 \\
1200 & 0.9198 \\
1300 & 0.9199 \\
1400 & 0.9200 \\
1500 & 0.9201 \\
1600 & 0.9202 \\
1700 & 0.9202 \\
\hline
\end{tabular}


been measured in situ and is given by Herron and Langway [1980].

Figure 3 displays the significance of various terms calculated in Appendix A. The horizontal line (labeled STP) is the laboratory density of ice at $0^{\circ} \mathrm{C}$ and atmospheric pressure. When the compressibility is taken into account, the curve labeled $P$ is obtained. Allowing also for temperature gives curve P,T. Finally, the effect of the bubbles is estimated, resulting in our final density prediction plotted as a solid line ( $P, T, B u b$.). As expected, the total correction is at the level of a few parts in $10^{3}$.

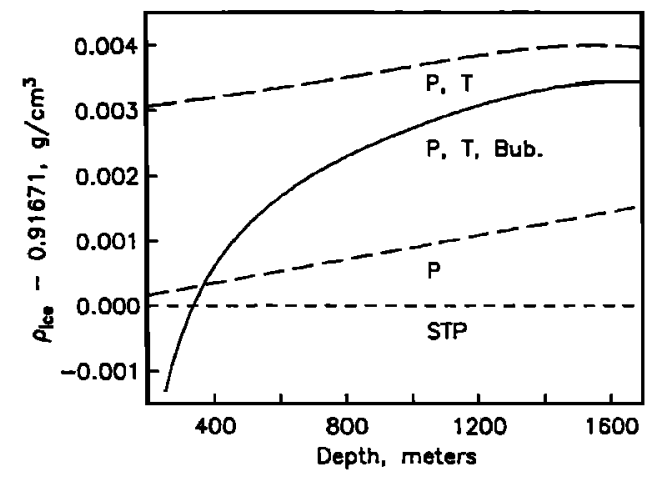

Fig. 3. A model of the ice density as a function of depth. The curve labeled "STP" is just the laboratory-determined density for ice at $0^{\circ} \mathrm{C}$ and atmospheric pressure. The curve labeled " $P$ " is the effect of compression from the overburden. The curve labeled "P, $T$ " takes into account the ice sheet's temperature profile as well as the pressure effect. Finally, the curve labeled "P, T, Bub." adds the effect of the air bubbles and represents our final model for ice density between 200 and $1800 \mathrm{~m}$ depth.

\section{Field Data Collection and Reduction}

Data collection for the 1987 Newtonian gravitational constant experiment began at Dye 3 on July 14, 1987. The beginning phase of the project was to set up a network of surface measurements to assess vertical variations of gravity in the Dye 3 borehole. A circular grid centered on the wellhead consisted of eight radial lines at $45^{\circ}$ spacing starting from $17^{\circ}$ true north (Figure 4). These lines were navigated using Global Positioning System (GPS) receivers, accurate to about $50 \mathrm{~m}$, and were marked with flags spaced at $200 \mathrm{~m}$. At radial distances of 2.6, 6.0 , and $16.0 \mathrm{~km}$ along each line, benchmarks were installed in the snow surface. The benchmarks consisted of $\sim 1 / 2-m-s q u a r e$ wooden platforms buried a little less than $1 \mathrm{~m}$ deep in the snow. A $1-m$ vertical wooden post attached to the center of each benchmark protruded slightly above the snow surface.

In addition to the borehole gravity measurements, surface gravity measurements were made at all 25 sites in the network. To interpret the gravity measurements, the heights of the observation points needed to be determined to an accuracy of a few centimeters. This was done using GPS for the outer eight sites and four of the inner sites (these are plotted as solid circles in Figure 4). The 16 intermediate and close-in sites were surveyed with conventional first-order leveling and Electronic Distance Meter (EDM) readings.

Radar echo-sounding data were obtained along 5-km-long radial lines centered at the Dye 3 station. The very dense sampling (the dots in Figure 4 indicate the region surveyed) allowed the gravity measurements in the borehole to be corrected for undulations in the ice-rock interface.

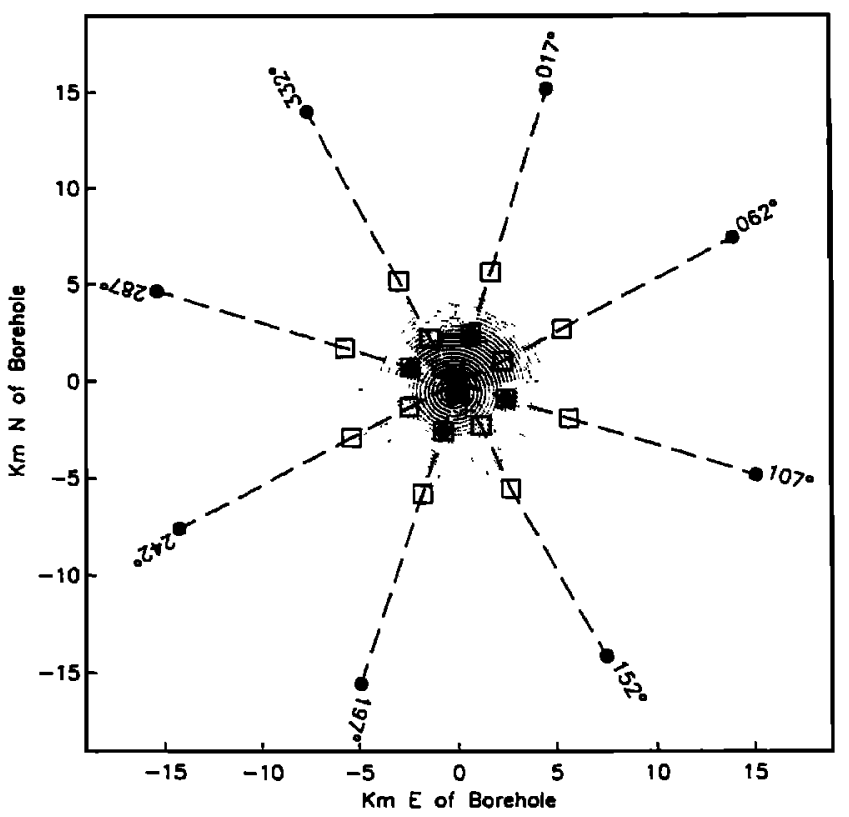

Fig. 4. A map of our surface surveys. GPS records were obtained at the points indicated by solid circles. Leveling and EDM surveys were performed to the points labeled with open boxes. Relative gravity observations were made at points indicated by both boxes and circles. The small dots indicate the region covered by radar echo-sounding measurements. (Only a subset of the coordinates for radar observations is plotted here; the actual sampling interval is much higher than shown.)

\section{GPS Survey}

Three dual-frequency GPS receivers (TI 4100's) were deployed in geodetic mode over the eight outer benchmarks and four of the inner benchmarks to record their precise positions relative to the wellhead. One of the receivers continually occupied a base station $504.9 \mathrm{~m}$ from the borehole, while the other two were deployed at the benchmarks.

Few GPS satellites were operating at the time of our experiment; there were only a few hours per day when four satellites (the number required for precise positioning) were visible. We used the receivers in navigation mode to establish the survey lines during periods in which only three satellites were visible. The receivers were available to our group for approximately a 2 -week period. In that time we obtained single observation sessions at 12 sites. Eight of these were in the outer ring $(16 \mathrm{~km}$ radius) and four were in the inner ring ( $2.6 \mathrm{~km}$ radius). This last set provided sites to compare with leveling.

Normal surveyor's tripods pushed into the snow to a depth of $20-30 \mathrm{~cm}$ were used to support the antenna. The tripods remained stable in 20-knot winds during the overnight periods of deployment, as evidenced by the repeatability of measurements from the antenna to the benchmarks before and after the recording periods. During the recording periods the receivers and recorders were housed in small tents placed some $20 \mathrm{~m}$ from the antenna.

The main difficulty encountered in reducing the GPS data was the frequent contamination with cycle-slips (B. Perin, UNAVCO, private communication, 1988). The cause of this may be unusual ionospheric activity during the campaign coupled with the site's proximity to the north magnetic pole [Beutler et al., 1990]. We have two cases in which the same 
site was observed in separate recording sessions and five sites in which leveling and GPS were done at the same benchmarks. Our assessment based on these comparisons (see Table 2) is that the vertical accuracy of the GPS survey was around $10 \mathrm{~cm}$.

The coordinates of the borehole benchmark, as determined by GPS, are latitude, $65^{\circ} 11^{\prime} 10.9789^{\prime \prime}$; longitude, $-43^{\circ} 49^{\prime} 7.3853^{\prime \prime}$; height with respect to 1984 ellipsoid, $2518 \mathrm{~m}$. All coordinates tabulated in this paper are referenced to a Cartesian frame centered at this point.

\section{Leveling}

Conventional positioning methods provided heights and horizontal locations for the inner two rings of gravity stations and three-dimensional positioning for the radar soundings. The leveling was accomplished with two Zeiss Jena Ni-002 compensated levels and two double-scaled Kem invar rods provided by the Instrumentation and Equipment Section of the National Geodetic Survey (NGS), Charting and Geodetic Services. Two total station EDM's were used also; these were a Zeiss Elta $5 / \mathrm{m}$ and a Wild TC2000 Tachymat Informatics with a Wild GRE Data Terminal, both with triple-prism cubical reflectors. These instruments correct for Earth curvature and mean refraction. The Wild instrument computes $x-y-z$ locations automatically. All levels and the Zeiss Total Station were calibrated by the NGS, and the Wild Total Station by the leasing company prior to shipment to Greenland.

The leveling was carried out along eight radial lines to the inner two rings of benchmarks (to a radial distance of $6 \mathrm{~km}$ ). These radial lines were centered on a base benchmark located at the wellhead. Maximum distances between setups were $60 \mathrm{~m}$, temperatures ranged from $0^{\circ} \mathrm{C}$ to $-20^{\circ} \mathrm{C}$, and visibility was usually good. To insure instrument stability, wooden support platforms made by J. H. Karlberg (Seattle, Washington) were used to provide support in the snow. Steel nails (15 cm in length) extended through the plates to provide lateral stability. Plastic minimum conductive turning "turtles" were built by the NGS to support the invar rods.

During the surveying, one snowmobile carried two invar rods while another pulled a sled with a wooden enclosure housing a small computer and an operator. Data were processed in the field as observations were made to check for consistency. Observations not meeting the requirements of at least third-order leveling were repeated. Loops were closed over each line beginning and ending at the wellhead benchmark. The closures indicate first-order accuracy was achieved in most cases. In three loops, closures were from 2 to $4.3 \mathrm{~cm}$ and are ascribed to "blunders" in measuring the distance from the rod to the benchmarks.

The 16 gravity stations in the inner two rings were surveyed by the Wild Total Station to obtain their lateral positions. A continuous loop started at the base benchmark connecting all 16 stations displayed closure of $1.10 \mathrm{~m},-0.15 \mathrm{~m}$, and $-0.30 \mathrm{~m}$ in $x, y$, and $z$, respectively.

The radar soundings (described in the following section) were positioned by placing one of the total stations on the roof of Dye 3 and ranging to retroreflectors mounted on the radar sled. Maximum observation distances were approximately $5 \mathrm{~km}$. Although the manufacturer's specifications indicate an accuracy in "fair" conditions of the order of centimeters, due to refraction effects the accuracy of the radar sled position is estimated to be of the order of $1 \mathrm{~m}$.

\section{Ice-Penetrating Radar}

The purpose of the radar survey was to provide an estimate of the location and shape of the ice-bedrock interface in three dimensions with sufficient accuracy that it could be used for topographic correction to measurements of gravity in the borehole.

Regional radar surveys [Gudmandsen and Christensen, 1972; Overgaard, 1978, 1979; Sondergaard, 1975; Jezek et al., 1985; Overgaard and Gundestrup, 1985] previously measured the ice thickness in the Dye 3 area, so the general characteristics of the bedrock topography were known. However, for the present experiment, these surveys could be considered to provide only reconnaissance level information, as they lack the required detail and accuracy. Thus a new survey was performed.

The radar equipment was a Scott Polar Research Institute (SPRI) Mark IV 60-MHz system [Evans and Smith, 1969; Gor. man and Cooper, 1987]. This system has a selectable pulse duration of 350 ns or $1 \mu \mathrm{s}$, receiver bandwidth of $15 \mathrm{MHz}$, peak transmitter power of $300 \mathrm{~W}$, system gain of $160 \mathrm{~dB}$ (not including antenna gain), and a two half-wave dipole-with-reflector antenna that has a $6-\mathrm{dB}$ forward gain and a $90^{\circ}$ half-power angular beam width. In each sample, 64 source excitations were stacked to increase the signal-to-noise ratio. The logarithmic receiver has about $60 \mathrm{~dB}$ of dynamic range. The output of the receiver is digitized with a sampling frequency of 32 MHz. The resulting digital data contain the log of the recorded reflected radar power as a function of time at each spatial position.

Approximately 450 soundings were made on each of 124 lines radiating from the Dye 3 complex to a distance of $5 \mathrm{~km}$. In all, about 42,000 usable radar reflections from the bedrock were recorded over an area of about $80 \mathrm{~km}^{2}$. Because the reflectors do not in general lie directly beneath the source, reconstruction of the bedrock topography from such data requires spatial repositioning of apparent reflector locations in addition to time-to-depth conversion. The algorithm used for this was originally developed for three-dimensional imaging of seismic data and is described by Wen and McMechan [1984, 1987]. With the substitution of the velocity of propagation of radio waves in ice for that of seismic waves in the Earth, the seismic algorithm is directly applicable to imaging of radar data.

The gross features in the resulting image of the bedrock surface obtained are consistent with those of the previous surveys but resolved a significantly greater level of detail with less uncertainty. The Dye 3 site is apparently above the eastern edge of a valley in the bedrock that trends approximately northwest-southeast, which is superimposed upon an overall dip of the rock surface toward the west. Estimated errors in over $70 \%$ of the survey area are less than $5 \mathrm{~m}$ in depth. A major factor in. this low uncertainty was the tie point of the rock surface provided by the drill hole. Details of the survey are presented by Fisher et al. [1989]. Note that 5-m uncertainties in depths of the rock-ice interface affect the experiment through the calculation of the gravitational attraction of the terrain; this issue is different from the much higher demand for accuracy in the depths of the borehole gravity measurements $(0.5 \mathrm{~m})$, governed by the gravity gradient in the borehole.

\section{Surface Gravity Measurements}

Relative gravity measurements at all 25 benchmarks in the network were made in multiple loops along each radial survey 
line with two model-G and two model-D LaCoste \& Romberg gravity meters. The meters were transported in shock-isolated boxes mounted on sleds pulled by snowmobiles. At each benchmark, a $30 \mathrm{~cm}$ by $30 \mathrm{~cm}$ platform was set into the snow surface to support the gravity meters. Heights of the platforms with respect to the benchmarks' wooden posts were recorded. Three-meter-high galvanized steel poles were attached to each benchmark to allow subsequent surveyors to locate them.

Although the snowmobiles were capable of speeds up to 80 $\mathrm{km} / \mathrm{h}$ the shocks from the crossing of wind-generated bumps in the snow surface (characterized by $5-10 \mathrm{~m}$ wavelength and $1 / 2$ $m$ amplitude) appeared to cause small tares in the meters. Loop closure was poor in the gravity survey unless the snowmobile speed was kept below $30 \mathrm{~km} / \mathrm{h}$. The statistics of the multiplemeter, multiple-loop survey indicate uncertainties of 10-15 $\mu \mathrm{Gal}$ for the surface gravity observations.

\section{Borehole Gravity}

During the survey of the benchmarks surrounding the borehole, the logging of the borehole itself was completed. After setting the winch in place and erecting the logging tower, the first week of effort was devoted to clearing the borehole; it had become clogged by chunks of ice from near-surface icicles and old drill cuttings. An additional week was required to log the hole for gravity and hole characteristics. Gravity measurements were made at $183-\mathrm{m}$ intervals to a depth of $1673 \mathrm{~m}$; directional logging was performed to a depth of $1840 \mathrm{~m}$.

Acquisition of borehole gravity data was begun at the lowermost station in the the borehole. The gravity meter was clamped and reread three separate times at each depth to assess the noise level of individual readings. (The last two readings at each station were used in the calculations.) The BHGM was then moved up to the next higher station and the process repeated until the top station had been occupied. Following this, the meter was again lowered to the bottom station and all stations rerun. Finally, the bottom station was occupied once more to control drift better. This process was repeated twice on consecutive days.

The standard deviation of the repeat readings for a single occupation was typically $7 \mu \mathrm{Gal}$. This is essentially equal to the repeatability observed during the meter's calibration in Alaska [Sasagawa et al., 1989]. The standard deviation over station reoccupations was $35 \mu \mathrm{Gal}$. If this were ascribed entirely to the depth error in subsequent station occupations, this would be equivalent to an $\mathrm{rms}$ error of about $15 \mathrm{~cm}$ in depth, as the gravity gradient in the ice is of the order of $0.2 \mathrm{mGal} / \mathrm{m}$.

Because of the deviation from vertical in the borehole, the BHGM depths determined by the calibrated wireline actually were borehole lengths: these had to be converted to true depths. Since the depth corrections were as large as $4 \mathrm{~m}$, they were extremely important and were done with two independent measurements. The first was the use of the tilt measurements from the borehole gravity meter itself. The meter must be leveled quite accurately in order to take a reading; it is leveled by a gimbal arrangement, and the tilt of the sonde from vertical can be determined by the position sensors of the gimbals with respect to the sonde. These readings were taken at all stations. Also, following the gravity logging, a continuous deviation survey was made with the Polar Ice Coring group's directional logging tool. The depth corrections from the gravity meter's tilt sensors and the directional survey agreed within $0.2 \mathrm{~m}$.

\section{TerRain CoRRection to the Gravity MEAsliRemeNTS}

The density contrast at the rough interface at the base of the ice sheet produces a significant component of the gravity observed in the borehole and on the surface. Making an accurate estimate of the terrain effect is conceptually trivial but computationally demanding. We assume initially a simple model in which a uniform basement is covered by uniform ice, so that only the density difference $\Delta \rho$ is required. Out to a radial distance of about $5 \mathrm{~km}$ from the wellhead the ice thickness and hence the basement relief was mapped by radar to extremely high resolution. The migrated image of the rock surface was sampled on a square grid having $125-\mathrm{m}$ spacing; the estimated errors in this image ranged from a fraction of a meter in the center to $2-3 \mathrm{~m}$ at $4 \mathrm{~km}$ from the borehole. This information is dense enough to compute the attraction by means of the classic integrals. We found the vertical attraction by two approximations: (1) we modeled the topography as a series of vertical, square-section prisms centered at each grid point; (2) we bisected each square of the grid by a diagonal line and modeled the interface as a set of triangular facets. In both cases the attraction of each element can be computed exactly in elementary functions.

As mentioned above, others had already measured ice thickness with surface and airbome radar out to $50 \mathrm{~km}$ from Dye 3 . The sampling density of these large-scale data is considerably less than for our close-in radar survey. Because the contribution to the terrain effect from topography outside our own survey is important, we incorporated the coarse data from the previous surveys.

Overgaard and Gundestrup [1985] used basement topography data determined from airbome radar surveys conducted in 1971, 1978, and 1979 [Gudmandsen and Christensen, 1972; Overgaard, 1978, 1979] merged with surface radar soundings collected in 1975 [Sondergaard, 1975] to construct a $1400 \mathrm{~km}^{2}$ map of the bedrock underlying Dye 3 . The airborne survey was conducted from a C-130 aircraft equipped with an inertial navigation system and a 10-kW, 60-MHz radar source. Flight \#0478 of the survey was performed specifically to yield a detailed map of the bedrock near Dye 3 and surveyed with an average track spacing of $8 \mathrm{~km}$. A $1-\mathrm{kW}$ surface radar transmitter was used along three $40-\mathrm{km}$-long ground tracklines emanating to the southwest of Dye 3 to supplement the flight data. We digitized the map from Overgaard and Gundestrup [1985], obtained the original data from Flight $\# 0478$, and merged them with our own survey.

The uncertainties in the three surveys vary, as do their average depths. Different sources of systematic error in each cause their levels to be shifted relative to one another. Our survey is referenced to the ellipsoid; the others are relative to the geoid. We shifted the outer maps vertically by $81 \mathrm{~m}$ to force the overlapping portions of previous surveys to agree with ours.

The terrain corrections for the gravity observations in the borehole and on the surface were computed from merged maps using two different algorithms. One relied on least squares collocation (see Appendix B), while the second was based on a digital terrain model (DTM). The DTM was constructed in three zones using the minimum curvature method of surface interpolation [Briggs, 1974] from the randomly scattered radar observation points. The minimum curvature method assumes a smoother surface than is actually appropriate for the rock topography, but it does produce a surface which is faithful to the observations. 
The grid density in the merged map (Figure 5) reflects the sample density of the data. The circular inner zone, of radius $4.5 \mathrm{~km}$, had a sample interval of $125 \mathrm{~m}$ and was based entirely on the surface radar survey. The outer zone was based on the digitized map of Overgaard and Gundestrup [1985] and the Flight \#0748 track lines and was gridded at a $1-\mathrm{km}$ interval. Each terrain sample was represented by a vertical prism, and the effects were summed to produce the terrain correction. The prisms were based on a reference elevation near the topographic mean.

The terrain effect spanned $20 \mathrm{mGal}$ among our surface sites; the two methods of calculating it agreed to better than $1 / 2 \mathrm{mGal}$ for surface points (better than this for borehole points; see below). The attraction of the terrain actually decreases with depth in the borehole owing to a local depression in the topography directly beneath the center of our survey.

The radial extent to which the terrain data had to be taken into account was determined empirically by truncating the topography data at smaller and smaller radii until the calculated terrain corrections changed. The numerical experiment indicated that the gravity effects of topographic undulations beyond a radius of $50 \mathrm{~km}$ were negligible.

To estimate the uncertainty of the overall terrain correction, accounting for the relatively low resolution of the airborne data, and to be able to estimate the contribution from even more distant terrain, another technique was invoked for the borehole observations and is described in Appendix B. The results of the analysis presented there are that the uncertainties in the terrain corrections amounted to several tenths of a millgal at many of the observation points. This is the dominating source of uncertainty in the corrected gravity values (see Tables 2 and 3 ),

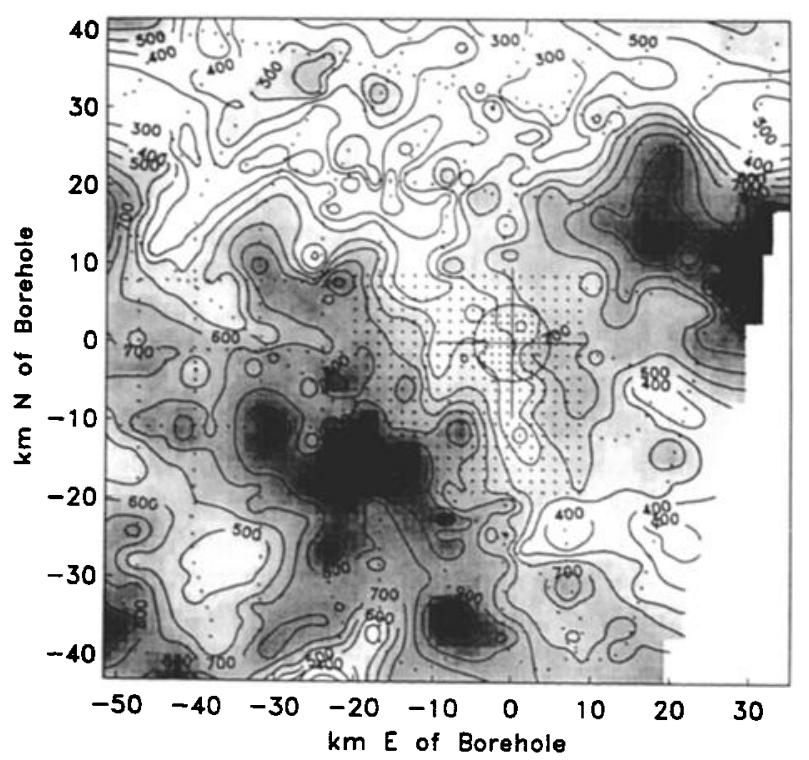

Fig. 5. A map of the bedrock topography as determined from (1) our own, high-precision radar survey (within the 5-km-diameter disk), (2) a digitization of the map assembled by Overgaard and Gundestrup [1985], and (3) and a series of airborne radar mapping missions. The contour levels are the bedrock heights in meters with respect to the ellipsoid. The circle centered on the Dye site's radar dome (less than $1 \mathrm{~km}$ from the borehole) denotes the region covered by our own radar survey. The rectangular grid of dots surrounding and offset from the borehole is our digitization of the map of Overgaard and Gundestrup [1985] gridded at $1.5 \mathrm{-km}$ spacing. The irregular track lines indicated beyond this radar survey are from survey Flight \#0478 described above. outweighing the other sources of uncertainty (including noise in the measurements, uncertainty in the ice density, and imperfect knowledge of the observation site coordinates) by a factor of nearly 10 .

\section{Fully CORRECTED GRAVITY SUMMARY}

Table 2 is a summary of the surface gravity observations. The Bouguer, terrain, and latitude entries are corrections (having sign opposite to that of the effect) and are added to the observed gravity values to compute the corrected gravity values. The Bouguer term was calculated using the standard local free-air gradient and an upper-ice-density profile modeled by

$$
\rho(z) \approx \rho_{0}\left[1+e^{-z / n}\right]^{-1} \quad 10 \mathrm{~m}<z<200 \mathrm{~m}
$$

with $\rho_{0}$ being the laboratory value of ice and $l$ being $36.4 \mathrm{~m}$ (this was estimated by fitting an exponential function to the data of Herron and Langway [1980, Figure A1, p. 383]).

Similarly, Table 3 is a summary of the borehole gravity survey. Again the free-air, ice, and terrain entries are corrections added to the observations to obtain corrected values. The freeair term combines with the ice attraction (compured using the laboratory value of $G$ ) to yield the so-called double Bouguer gradient. They are separated in this presentation to emphasize that it is the attraction of the ice slab bounded by our borehole profile that provides the signal to evaluate $G$. This illustrates one of the important differences between this type of experiment (an Airy experiment) and a tower experiment [Eckhardt et al., 1988; Thomas et al., 1989]; the former can determine $G$ independently (except for the adoption of an Earth model), whereas the latter cannot without making additional assumptions. An Airy experiment is really a large-scale Cavendish experiment and directly yields $G$ because the mass of the attracting material is taken into account explicitly. Only in conjunction with laboratory experiments and the postulation of a new force law (such as a Yukawa law) can a tower experiment be used to extract $G$ at long range.

At this stage of the analysis the gravity observations are corrected for all known effects, including the attraction of the rock beneath the ice. The remaining anomaly in the borehole data, plotted in Figure 6, is a candidate for evidence that $G$, at distances larger than are available in laboratory experiments, is smaller by about $3 \%$.

Up to this point, the rock beneath the ice has been treated as a completely uniform solid. However, density variations in the rock can produce vertical gravity gradients. Such gradients from distant sources (say, $100 \mathrm{~km}$ deep) can be shown to be small compared with the observed anomaly. Appendix $C$ assesses the anomalous gravity gradient from deep mass anomalies using an Earth model expressed in spherical harmonics to degree 360 . The effects of local masses, however, cannot be shown to be unimportant.

An unsuccessful attempt was made to determine the perturbation to the local free-air gradient directly by observing the variation in $g$ with height on the Dye 3 building. A platform approximately $30 \mathrm{~m}$ above the ice surface could accommodate a person with a gravity meter. The wind imparted significant vibrations to the structure, making the gravity meter readings noisy. Three meters were employed in multiple loops between the ice surface and the platform, and the exact height was measured with an EDM. The average gradient thus determined agreed with the theoretical local gradient modified by our calcu- 
TABLE 2. Surface Gravity Measurements near Dye 3

\begin{tabular}{|c|c|c|c|c|c|c|c|c|}
\hline $\begin{array}{l}x \\
\mathrm{~m}\end{array}$ & $\begin{array}{l}y \\
\mathrm{~m}\end{array}$ & $\begin{array}{c}z_{\mathrm{GPS}} \\
\mathrm{m}\end{array}$ & $\begin{array}{c}z_{\text {Leveling }} \\
\mathrm{m}\end{array}$ & $\begin{array}{c}\text { Observed } g, \\
\text { mGal }\end{array}$ & $\begin{array}{c}\text { Bouguer } \\
\text { mGal }\end{array}$ & $\begin{array}{c}\text { Terrain } \\
\text { mGal }\end{array}$ & $\begin{array}{c}\text { Latitude } \\
\text { mGal }\end{array}$ & $\begin{array}{c}\text { Corrected } g \\
\text { mGal }\end{array}$ \\
\hline 0.0 & 0.0 & 0.000 & 0.000 & 0.000 & 0.00 & 0.00 & 0.00 & $0.0 \pm 0.3$ \\
\hline 683.0 & 2453.4 & -8.576 & -8.744 & 4.706 & -2.35 & -1.11 & -1.52 & $-0.3 \pm 0.3$ \\
\hline 1725.2 & 5662.7 & & -20.073 & 10.147 & -5.51 & -4.01 & -3.52 & $-2.9 \pm 0.3$ \\
\hline 4599.1 & 15204.9 & -43.461 & & 23.772 & -12.01 & -7.53 & -9.44 & $-5.2 \pm 0.5$ \\
\hline 2306.9 & 1088.6 & & -10.018 & 6.894 & -2.75 & -3.19 & -0.68 & $0.3 \pm 0.3$ \\
\hline 5341.7 & 2737.4 & & 8.031 & 16.152 & 2.19 & -6.65 & -1.70 & $10.0 \pm 0.3$ \\
\hline 14002.4 & 7418.1 & -81.553 & & 40.019 & -22.83 & -12.64 & -4.61 & $-0.1 \pm 0.5$ \\
\hline 2438.5 & -841.9 & -10.527 & -10.621 & 8.104 & -2.89 & -4.69 & 0.52 & $1.0 \pm 0.3$ \\
\hline 5720.9 & -1871.7 & & -18.721 & 13.083 & -5.14 & -9.11 & 1.16 & $-0.0 \pm 0.3$ \\
\hline 15139.8 & -4802.2 & -54.330 & & 20.879 & -15.06 & -0.59 & 2.98 & $8.2 \pm 0.5$ \\
\hline 1185.9 & -2224.3 & & 1.730 & 1.353 & 0.47 & -2.37 & 1.38 & $0.8 \pm 0.3$ \\
\hline 2684.3 & -5488.6 & & 3.646 & -5.440 & 0.99 & -2.18 & 3.41 & $-3.2 \pm 0.3$ \\
\hline 7535.4 & -14110.9 & 4.608 & & -11.226 & 1.26 & -3.63 & 8.76 & $-4.8 \pm 0.5$ \\
\hline-713.8 & -2523.9 & 11.698 & 11.649 & -6.871 & 3.19 & 1.05 & 1.57 & $-1.1 \pm 0.3$ \\
\hline-1752.7 & -5747.8 & & 11.491 & -11.410 & 3.13 & -0.33 & 3.57 & $-5.0 \pm 0.3$ \\
\hline-4890.8 & -15504.4 & 48.120 & & -11.030 & 13.08 & -14.17 & 9.63 & $-2.5 \pm 0.5$ \\
\hline-2387.7 & -1271.3 & & 12.183 & -8.904 & 3.32 & 2.14 & 0.79 & $-2.7 \pm 0.3$ \\
\hline-5342.7 & -2851.4 & & 15.799 & -7.723 & 4.31 & -0.68 & 1.77 & $-2.3 \pm 0.3$ \\
\hline-14224.2 & -7568.0 & 61.586 & & -10.617 & 16.72 & -15.26 & 4.70 & $-4.5 \pm 0.5$ \\
\hline-2358.2 & 764.4 & 4.849 & 4.952 & -6.157 & 1.32 & 2.06 & -0.47 & $-3.3 \pm 0.3$ \\
\hline-5678.2 & 1765.8 & & 8.879 & -10.400 & 2,42 & 3.69 & -1.10 & $-5.4 \pm 0.3$ \\
\hline-15348.1 & 4660.3 & 36.461 & & -12.691 & 9.92 & -1.39 & -2.89 & $-7.1 \pm 0.5$ \\
\hline-1342.6 & 2257.8 & & 2.803 & -2.007 & 0.76 & 0.81 & -1.40 & $-1.8 \pm 0.3$ \\
\hline-2928.4 & 5209.5 & & 2.451 & -2.129 & 0.67 & 1.87 & -3.24 & $-2.8 \pm 0.3$ \\
\hline-7604.4 & 14025.5 & 1.480 & & -1.812 & 0.40 & 6.98 & -8.71 & $-3.1 \pm 0.5$ \\
\hline
\end{tabular}

lated terrain effect. Despite internal consistency of $20-30 \mu \mathrm{Gal}$ in the single-meter readings, however, the means from the three meters showed scatter approaching $100 \mu \mathrm{Gal}$. This uncertainty, when scaled to the depth interval surveyed in the borehole, grew to a magnitude comparable to the anomaly, rendering this measured gradient useless.

\section{DATA ANALYSIS AND INTERPRETATION}

\section{The Effects of Local Masses}

Two lines of evidence point to the existence of significant heterogeneities in the composition of the rock beneath the ice. First, geological studies of the coastal regions of Greenland show that mafic intrusions with densities from 2.8 to $3.0 \mathrm{~g} / \mathrm{cm}^{3}$ are found within the metamorphic basement. These highdensity intrusives occupy only a few percent of the exposed basement rock [Windley, 1984]. Second, our own surface gravity map reveals anomalies within our network. They are typically $3 \mathrm{mGal}$ but in one case the anomaly reaches $10 \mathrm{mGal}$.

Figures $7 a$ and $7 b$ are profiles of fully corrected surface gravity data along two perpendicular lines crossing Dye 3 . If the rock were of uniform density these profiles would be flat. The gravity field is fairly constant, confirming our assertion in Appendix $C$ that deeply rooted mass anomalies cannot account for the anomalous gradient in the borehole. The general flatness of the field is further contirmed by Figure 6 of Jezek et al. [1985]. Their gravity measurements in the region were the only ones available during the design of our experiment.

However, our sampling of the field is not very dense and includes one rather large anomaly. Modeling of this $10-\mathrm{mGal}$ anomaly with, for example, a compact spherical source directly below the observation point does not predict a large gradient near the borehole. Of course, only a few forward models can be tested. Before claiming that conventional physics is inadequate, we must resort to inverse theory in an attempt to find a Newtonian model that fits both the borehole data and the surface data.

\section{Ideal-Body Analysis}

To demonstrate unambiguously the inadequacy of a purely Newtonian explanation, one must show that any reasonable density variation in the basement that produces the observed anomalous borehole gravity profile is inconsistent with the surface gravity survey. It is well known that even complete gravity information outside a body cannot uniquely determine the internal density structure. However, the theory of ideal bodies [Parker, 1974, 1975; Ander and Huestis, 1987] leads to a rigorous calculation of the smallest possible density contrast that

TABLE 3. Borehole Gravity Measurements near Dye 3

\begin{tabular}{|c|c|c|c|c|c|c|c|}
\hline $\begin{array}{l}x, \\
\mathrm{~m}\end{array}$ & $\begin{array}{l}y, \\
\mathrm{~m}\end{array}$ & $\begin{array}{l}z, \\
\mathrm{~m}\end{array}$ & $\begin{array}{c}\text { Observed } g \\
\text { mGal }\end{array}$ & $\begin{array}{c}\text { Free Air } \\
\text { mGal }\end{array}$ & $\begin{array}{l}\text { Ice, } \\
\text { mGal }\end{array}$ & $\begin{array}{c}\text { Terrain } \\
\mathrm{mGal}\end{array}$ & $\begin{array}{c}\text { Corrected } g \\
\text { mGal }\end{array}$ \\
\hline-2 & 0 & -213.22 & 0.00 & 0.00 & 0.00 & 0.00 & $0.00 \pm 0.26$ \\
\hline-5 & 0 & -396.12 & 42.39 & -56.37 & 14.06 & 0.25 & $0.33 \pm 0.25$ \\
\hline-9 & 0 & -579.00 & 84.72 & -112.74 & 28.13 & 0.52 & $0.63 \pm 0.23$ \\
\hline-15 & 1 & -761.83 & 127.13 & -169.09 & 42.21 & 0.82 & $1.07 \pm 0.20$ \\
\hline-22 & 1 & -944.63 & 169.48 & -225.45 & 56.31 & 1.14 & $1.48 \pm 0.19$ \\
\hline-48 & 9 & -1309.40 & 254.10 & -337.91 & 84.44 & 1.92 & $2.55 \pm 0.15$ \\
\hline-68 & 12 & -1491.18 & 296.32 & -393.97 & 98.47 & 2.40 & $3.22 \pm 0.13$ \\
\hline-90 & 17 & -1673.23 & 338.51 & -450.11 & 112.52 & 2.95 & $3.87 \pm 0.25$ \\
\hline
\end{tabular}




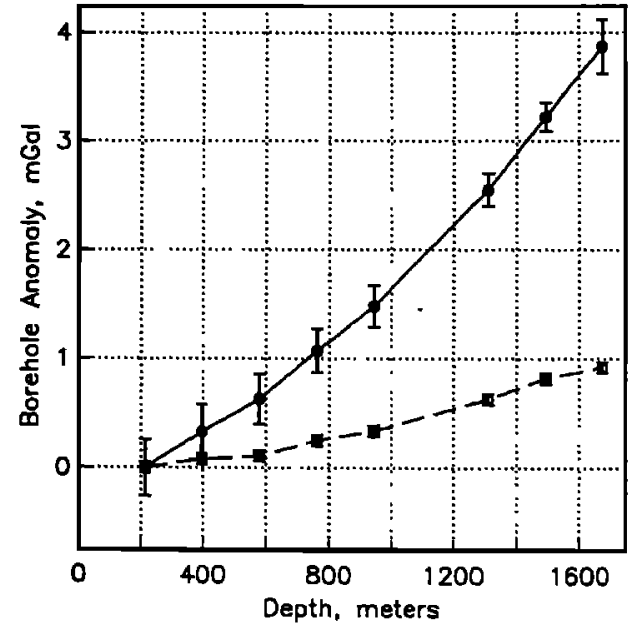

Fig. 6. The gravity anomaly in the borehole with all corrections except the effect of bedrock topography is plotted with open circles; the solid circles are the data including the terrain correction.

is mathematically consistent with a finite number of gravity observations. If such a calculation showed that a geologically unacceptable density contrast was required to produce the measured gravity values, the case for a modification of Newton's law of gravity would be made.

The application of ideal-body theory involves optimizing a parameter (in our case, the discrepancy between the model gravity field and the observations). Here we present a simplified view of the process. A finite section of the Earth lying beneath a group of gravity observations is divided into $N$ cuboidal cells. The gravity field generated by filling a subset of the cells with density $\Delta p$ is compared with the observations; the level of agreement is quantified in the usual way with

$$
\chi^{2}(\Delta p)=\sum_{j=1}^{N} \frac{1}{\sigma_{j}^{2}}\left\{\Delta g_{j}-\Delta g_{j}\right\}^{2}
$$

where the $\Delta g$, are the observations with uncertainties $\sigma_{J}$ and the $\Delta g_{j}{ }^{\prime}$ are the gravity values generated by the filled cells. When $\chi^{2} / N$ is of order unity or less, the model fits the data. For a given density, the distribution of filled cells is iteratively altered, both in number and in location of filled cells, until the fit is optimized. This process is repeated with smaller and smaller density contrast until the observations can no longer be matched. The density where the transition from fitting to not fitting occurs is the least upper bound on the maximum density contrast.

Because all the gravity measurements are relative, some arbitrary constant may be added to each one. In fact, to avoid the necessity of huge anomalous masses whose presence would be inconsistent with geological considerations, we allow an offset as a parameter in our fit. Since our gravity survey reveals variations in the corrected surface gravity of up to $10 \mathrm{mGal}$, values of this order for the arbitrary constant are acceptable, but values several times larger would be difficult to justify.

The smallest density contrast needed to explain the Greenland data set with conventional physics is $0.3 \mathrm{~g} / \mathrm{cm}^{3}$ when a regional offset in the field of $10 \mathrm{mGal}$ is allowed. Table 4 lists the borehole and surface gravity observations, the gravity field modeled with an ideal body having $0.3 \mathrm{~g} / \mathrm{cm}^{3}$ density contrast, and the differences between observations and model. Because the differences are mostly within the uncertainties of the observations, the model is considered as fitting the data.

The actual distribution of the filled cells is, for the most part,

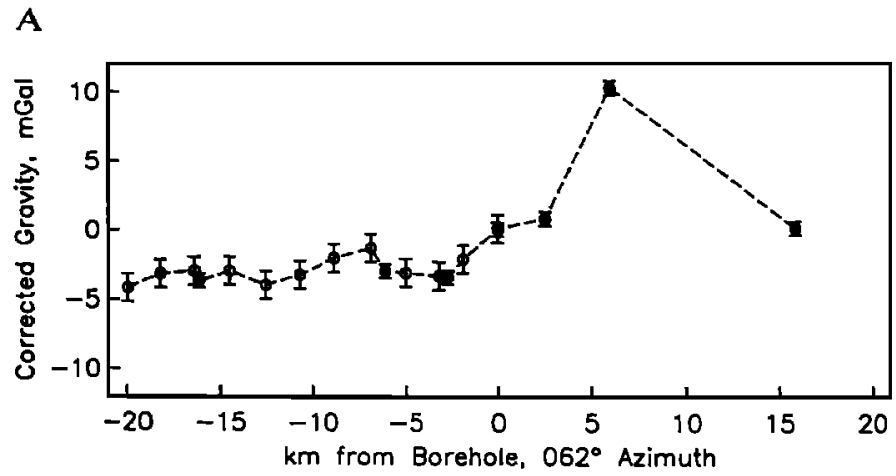

B

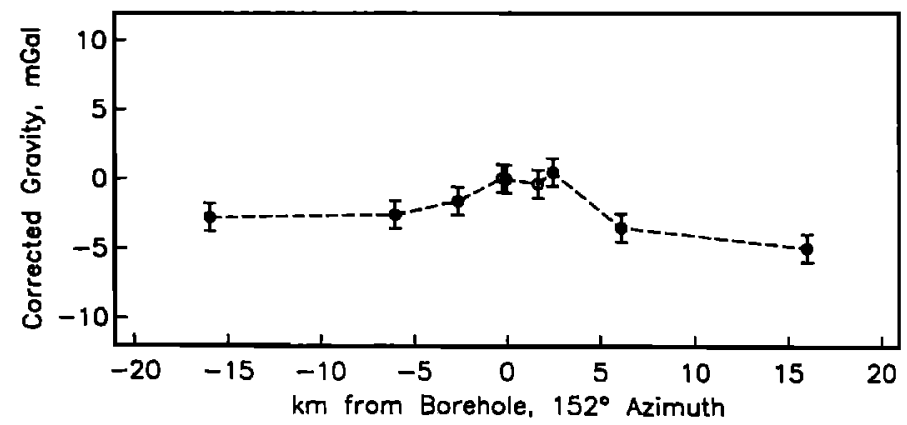

Fig. 7. Gravity profiles along the ice surface. All corrections, including sub-ice terrain effect, are included. The solid circles represent our own observations and the open circles those of Jezek et al. [1985]. (a) Profile along bearing $062^{\circ}$ (with respect to true north). (b) Profile along a line bearing $152^{\circ}$. 
TABLE 4. Ideal-Body Fit

\begin{tabular}{|c|c|c|c|c|c|}
\hline $\begin{array}{l}x \\
\mathrm{~m}\end{array}$ & $\begin{array}{l}y, \\
\mathrm{~m}\end{array}$ & $\begin{array}{l}\mathrm{z}, \\
\mathrm{m}\end{array}$ & $\begin{array}{c}\text { Corrected } g \text {, } \\
\mathrm{mGal}\end{array}$ & $\begin{array}{c}\text { Modeled } g, \\
\mathrm{mGal}\end{array}$ & $\begin{array}{l}\text { Misfit } \\
\text { mGal }\end{array}$ \\
\hline \multicolumn{6}{|c|}{ Surface Observations } \\
\hline 0 & 0 & 0 & 0.0 & 0.1 & -0.1 \\
\hline 683 & 2453 & -9 & -0.3 & -0.6 & 0.3 \\
\hline 1725 & 5663 & -20 & -2.9 & -2.1 & -0.8 \\
\hline 4599 & 15205 & -43 & -5.2 & -5.2 & 0.0 \\
\hline 2307 & 1089 & -10 & 0.3 & 1.2 & -0.9 \\
\hline 5342 & 2737 & 8 & 10.0 & 9.0 & 1.0 \\
\hline 14002 & 7418 & -82 & -0.1 & 0.1 & -0.1 \\
\hline 2438 & -842 & -11 & 1.0 & 0.8 & 0.2 \\
\hline 5721 & -1872 & -19 & -0.0 & 0.5 & -0.5 \\
\hline 15140 & -4802 & -54 & 8.2 & 8.2 & 0.0 \\
\hline 1186 & -2224 & 2 & 0.8 & 0.6 & 0.2 \\
\hline 2684 & -5489 & 4 & -3.2 & -3.2 & 0.0 \\
\hline 7535 & -14111 & 5 & -4.8 & -4.8 & 0.0 \\
\hline-714 & -2524 & 12 & -1.1 & -0.9 & -0.2 \\
\hline-1753 & -5748 & 11 & -5.0 & -5.0 & -0.0 \\
\hline-4891 & -15504 & 48 & -2.5 & -2.5 & 0.0 \\
\hline-2388 & -1271 & 12 & -2.6 & -2.7 & 0.1 \\
\hline-5343 & -2851 & 16 & -2.3 & -2.4 & 0.1 \\
\hline-14224 & -7568 & 62 & -4.5 & -4.5 & 0.0 \\
\hline-2358 & 764 & 5 & -3.2 & -2.9 & -0.3 \\
\hline-5678 & 1766 & 9 & -5.4 & -5.4 & 0.0 \\
\hline-15348 & 4660 & 36 & -7.0 & -7.0 & 0.0 \\
\hline-1343 & 2258 & 3 & -1.8 & -1.9 & 0.1 \\
\hline-2928 & 5209 & 2 & -2.8 & -2.9 & 0.1 \\
\hline-7604 & 14026 & 1 & -3.1 & -3.2 & 0.1 \\
\hline \multicolumn{6}{|c|}{ Borehole Observations } \\
\hline-2 & 0 & -213 & 0.56 & 0.47 & 0.09 \\
\hline-5 & 0 & -396 & 0.89 & 0.80 & 0.09 \\
\hline-9 & 0 & -579 & 1.19 & 1.17 & 0.02 \\
\hline-15 & 1 & -762 & 1.63 & 1.58 & 0.05 \\
\hline-22 & 1 & -945 & 2.05 & 204 & 0.01 \\
\hline-48 & 9 & -1309 & 3.12 & 3.12 & 0.00 \\
\hline-68 & 12 & -1491 & 3.78 & 3.77 & 0.01 \\
\hline-90 & 17 & -1673 & 4.43 & 4.51 & -0.08 \\
\hline
\end{tabular}

irrelevant because it is not unique. The solution represents the pathological minimum allowable density contrast which bounds an infinite number of models having larger density contrasts that would fit the data with completely different distributions. For completeness, however, we present the ideal body in Figures $8 a$ and $8 b$. Figure $8 a$ displays where the body intersects the ice-

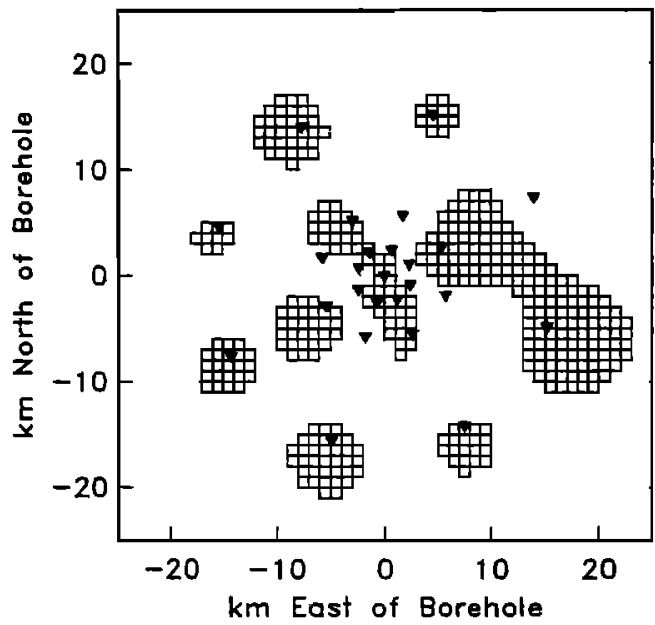

Fig. 8a. A map view of the intersection of the gravity ideal body with the bedrock-ice interface. The triangles denote the sites of our surface gravity observations. The small boxes denote filled cells in the ideal body.

rock surface (the boxes representing filled cells) and how the body is correlated with the observation points. Figure $8 b$ is simply an isometric view of the body to show its vertical extent; the cells are cubes with $1-\mathrm{km}$ edges.

Again, this should not be thought of as the actual body, it is merely one possible body, and the one which best matches the observations while requiring the smallest density contrast. The spatial correlation of the body with the observation points is purely an artifact of the ideal-body algorithm seeking the best fit to the data regardless of its shape. The central point is that 0.3 $\mathrm{g} / \mathrm{cm}^{3}$ is the smallest density contrast needed to fit the data. Because this is possible in a geologic sense, we cannot rule out Newton's law.

\section{Non-Newtonian Analysis}

A second interpretation of the borehole gravity anomaly is that it results from a scale-dependent non-Newtonian term in gravity. Because one obvious explanation of a violation of the inverse square law would be the existence of an exchange particle (or particles) having finite mass, a finite-range Yukawa

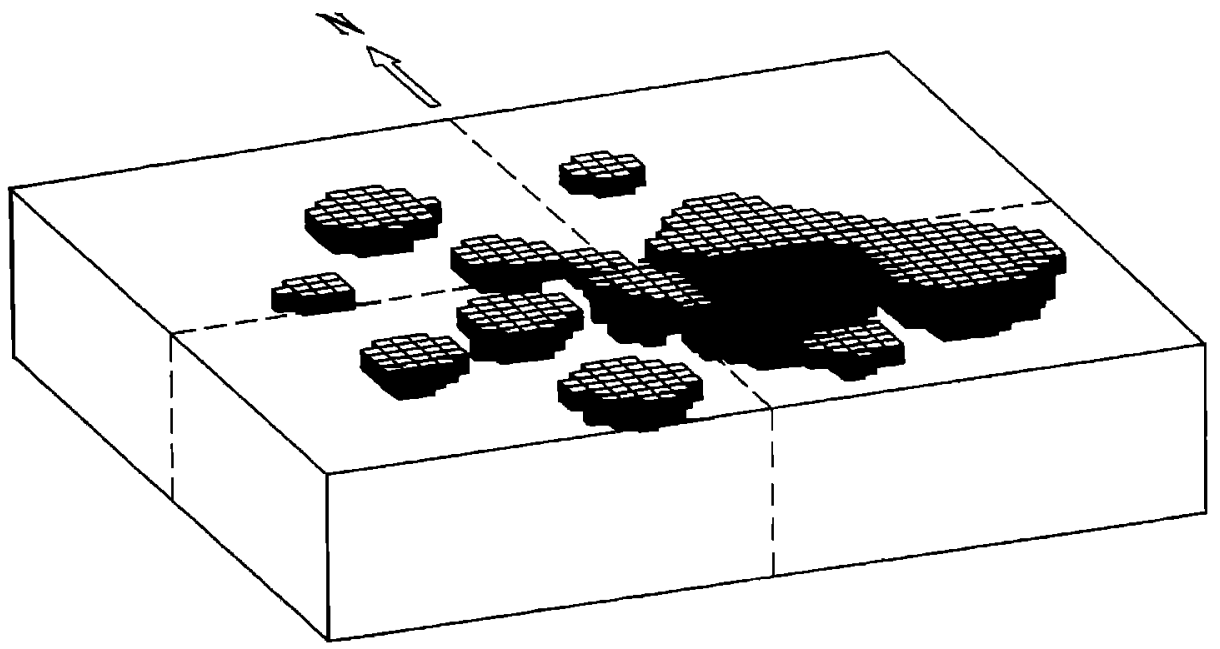

Fig. $8 b$. An isometric view of the ideal body in Figure $8 a$. Dimensions of the solution space are $50 \mathrm{~km}$ by $50 \mathrm{~km}$ by $10 \mathrm{~km}$ deep, centered on the borehole. The cells are $1-\mathrm{km}$ cubes. 
potential of the form

$$
V(r)=G m_{1} m_{2} r^{-1}\left(1+\alpha e^{-r / \lambda}\right)
$$

has been proposed. Nieto et al. [1989] present a fit to equation (8) using the Dye 3 borehole anomaly. There it is reported that within $\chi^{2}$ per degree of fref lom of 1.0 , the data show evidence for a new attractive force with values of $(\alpha, \lambda)$ that range between $(0.024,5.4 \mathrm{~km})$ and $(0.035,225 \mathrm{~m})$, with a best fit of $(0.031,805 \mathrm{~m})$. The results from that analysis are scaled in terms of a factor $\varepsilon(0 \leq \varepsilon \leq 1)$ defined as the fraction of the observed gravity anomaly that is caused by a Yukawa force and not buried density variations. The value of $\varepsilon$ cannot be determined using the information we have in hand now, but the Newtonian case $(\varepsilon=0)$ is still viable. Details of the fitting procedure and the scaling of $\alpha$ and $\lambda$ with $\varepsilon$ are given by Nieto et al. [1989].

\section{CONCLUSIONS}

We found an anomalous variation in gravity with depth that could not be explained by the effects of topography, imperfect knowledge of ice density, or uncertainties in the depth and gravity measurements themselves. Gravity anomalies at some of the surface observation points near the borehole suggested the possibility that the anomalous gravity gradient in the borehole could be due to density variations in the rock beneath the ice. This possibility was investigated using gravity ideal-body theory. We systematically varied $\rho_{0}$, the bound on the contrast between the sub-ice host rock and a postulated ideal body, and calculated the smallest possible misfit to the gravity observations. A good fit can be obtained for large but plausible density contrasts and acceptable offset values. Figure $8 a$ (out to $22 \mathrm{~km}$ ) implies that the high density intrusives are greater than $25 \%$ of the area beneath the borehole, while approximately $2 \%$ of the exposed coastal rocks are of this high density [Windley, 1984]. On the other hand, nearly identical ideal bodies fit the surface data alone, suggesting that dense intrusives are required by the data. We have found an anomalous gravity gradient that could be taken as evidence for non-Newtonian gravity. We have quantified this possibility by using regional gravity offset and density contrast as parameters to fit in an ideal-body analysis. This analysis finds that the data can be mathematically fitted with Newtonian gravity if one allows sufficiently large mafic intrusions in the bedrock.

We must emphasize that while we have failed to confirm non-Newtonian behavior of gravity, we have not shown that the inverse square law is accurate on scales of the order of $500 \mathrm{~m}$. Our experience suggests that, to be more sensitive, measurements of vertical profiles need to be complemented with more complete lateral gravity surveys.

\section{APPENDIX A: ICE DENSITY}

In the analysis below, we calculate the density profile of a slab of ice with a known temperature profile and a constant (by mass) air content compressed under its own weight. Except for the very near surface layers, this is a very close approximation to the situation on the Greenland ice sheet. Although the surface is not perfectly flat (we calculate the size of this effect elsewhere), we can ignore the density structure of the material above the depth of our shallowest measurement.

First consider only the effect on density of increasing pressure with depth. Pure ice at $0^{\circ} \mathrm{C}$ and atmospheric pressure has an accurately known density of $\rho_{\text {ice }}(0)=0.91671 \pm 0.00005$ $\mathrm{g} / \mathrm{cm}^{3}$ [Hobbs, 1974]. The ice compressibility $K^{-1}$ (defined from $\Delta V / V=-\Delta P / K$, where $V$ is volume) is $11.1 \mathrm{Mbar}^{-1}$ (or $K=9.01 \times 10^{9} \mathrm{~Pa}$ ). For constant temperature and infinitesimal strain, the density function of an elastic material in a uniform gravitational field can be calculated from

$$
\frac{d P}{d z}=\rho g
$$

meaning that

$$
\frac{d}{d z} \rho(z)=\rho(z) \rho(0) g K^{-1}
$$

This has the solution

$$
\rho(z)=\rho(0) e^{z / a}
$$

where the scale length $a=K\left(\rho_{0} g\right)^{-1}=1001 \mathrm{~km}$ for ice. This large scale length allows the approximation

$$
\rho(z) \approx \rho(0)\left(1+z \rho(0) g K^{-1}\right) \approx \rho(0)\left(1+K^{-1} \Delta P\right)
$$

Of course, the ice includes air trapped by the gradual transformation of snow to ice. The amount of air trapped in the ice has been measured by weighing ice cores from various depths before and after the sample was melted (i.e., with and without the air included) and has been found to be approximately constant at $110 \mathrm{~mL}$ of air per kilogram of ice [Herron and Langway, 1980; Raynaud and Lebel, 1979]. This translates to a ratio by volume at one atmosphere pressure of

$$
\frac{V_{\text {arr }}(0)}{V_{\text {ice }}(0)}=0.1008
$$

assuming a density of air at the surface of $\rho_{\text {air }}(0)=1.3 \times 10^{-3}$ $\mathrm{g} / \mathrm{cm}^{3}$.

To calculate the bulk density

$$
\rho(z)=\frac{m_{1 c e}+m_{\text {air }}}{V_{\text {ice }}(z)+V_{\text {air }}(z)}
$$

we consider the change in volume of a conserved mass of an ice-air mixture as the pressure is increased. The ice volume is governed by equation (A4), giving

$$
V_{\text {ice }}(z)=V_{\text {ice }}(0)\left[1-K^{-1} P(z)\right]
$$

The air volume is govemed by the perfect gas law, giving

$$
V_{\text {air }}(z)=\frac{P(0)}{P(z)} V_{\text {air }}(0)
$$

Combining equations (A6) and (A7) with equation (A5) gives

$$
\rho(z)=\rho_{\text {cce }}(0)\left\{\frac{1+\frac{\rho_{\text {air }}(0)}{\rho_{\text {ice }}(0)} \frac{V_{\text {arr }}(0)}{V_{\text {ice }}(0)}}{1-K^{-1} P(z)+\frac{P(0)}{P(z)} \frac{V_{\text {air }}(0)}{V_{\text {ice }}(0)}}\right\}
$$

Rearranging and keeping only terms larger than order $10^{-4}$ results in

$$
\begin{aligned}
\rho(z)= & \rho_{\text {ice }}(0) \\
& \left\{1+K^{-1} P(z)-\beta \Delta T(z)-\frac{V_{\text {air }}(0)}{V_{\text {ice }}(0)}\left[\frac{P(0)}{P(z)}-\frac{\rho_{\text {air }}(0)}{\rho_{\text {ice }}(0)}\right]\right\}
\end{aligned}
$$

The first-order thermal effect has been added into this expression. Second-order thermal terms such as the thermal expansion of the air in the ice have been omitted. The compressibility of 
ice has a slight temperature coefficient, but it varies by less than $5 \%$ over the range of temperature at the Dye site.

Other impurities are found in two forms: dust content and isotopic variation. Dust that has been deposited on the surface has accumulated in small but detectable amounts throughout the ice [Hammer et al., 1985]. These microparticles of clay and sea salts have concentrations of less than $50 \mu \mathrm{g} / \mathrm{kg}$, and are therefore negligible for our purposes. Such is also the case for isotopic variations. Although the amount varies, the ice typically contains $99.7 \%{ }^{1} \mathrm{H}_{2}{ }^{16} \mathrm{O}$, about $0.3 \%{ }^{1} \mathrm{H}_{2}{ }^{18} \mathrm{O}$, and minute amounts of both ${ }^{1} \mathrm{H}_{2}{ }^{17} \mathrm{O}$ and $\mathrm{HD}^{16} \mathrm{O}$. The effect on density, then, is about 3 parts in $10^{4}$, which is just short of requiring a correction.

Equation (A8), then, is our ice-density model for the portion of the ice bounded by our borehole gravity measurements $(213 \mathrm{~m} \leq z \leq 1673 \mathrm{~m})$. For the purposes here, a zeroth-order pressure profile $P(z)=\rho_{\text {ice }}(0) g z$ is sufficient. (An iterative approach in which the calculated density profile is used to calculate a pressure profile and then used in (A8) to calculate a new density profile does not provide significantly different results.) The temperature profile $T(z)$ was obtained from borehole temperature surveys [Gundestrup and Hansen, 1984].

The model ignores one physical aspect of the real ice: a phase transition of the trapped gas in the bubbles. At a depth of approximately $1200 \mathrm{~m}$, the bubbles in the ice samples disappear. At this depth the pressure is sufficiently high that air bubbles form air hydrates, the density of which is not significantly different from that of the host ice. The effect is an increase in the density of $7 \times 10^{-4}$, which we ignore.

An alternative approach at handling the gas content was attempted with similar results. In examinations of the ice cores, the bubble diameters and number density have been determined [Shoji and Langway, 1985]. A model based on this counting of bubbles rather than on the weighing of cores is probably less accurate, yet it agrees with the density calculated from the model described above to one part in $10^{3}$ over most of the hole.

The density of the ice at depths shallower than $200 \mathrm{~m}$ is poorly estimated by this model. This is due to the process of firn densification, in which pores in the ice near the surface are still connected to the atmosphere and do not become sealed until a depth of around $80 \mathrm{~m}$, where the density has been measured to be $=0.83 \mathrm{~g} / \mathrm{cm}^{3}$ [Herron and Langway, 1980]. This, incidentally, is consistent with the the measured ratio of $V_{\text {arr }}(0) / V_{\text {ice }}(0)$, from which one would expect the density of pore closure to be

$$
\rho_{\text {pore closure }} \approx\left[1-\frac{V_{\text {arr }}(0)}{V_{\text {ice }}(0)}\right] \rho_{\text {cce }}(0)=0.82 \mathrm{~g} / \mathrm{cm}^{3}
$$

To first-order, our model's poor prediction of the shallow density is unimportant since a horizontal slab of infinite lateral extent contributes nothing to the gravity gradient. However, the slab bounded by the surface and the depth of our highest gravity measurement is neither horizontal nor laterally infinite and does produce a gravity gradient in the borehole. Furthermore, the Bouguer correction to the surface gravity requires the density of the shallow layers be known with moderate precision. Fortunately, this region is adequately sampled, and an empirical density model is available that includes sampling over a broad area [Herron and Langway, 1980]. Thus we use two density models, one for the calculation of $G$ from borehole gravity measurements, used in the interval from $200 \mathrm{~m}$ to $1700 \mathrm{~m}$, and a second one for taking into account snow surface topography effects, used in the interval from 0 to $200 \mathrm{~m}$.

\section{APPENDIX B: SUB-ICE TERRAIN EFFECT}

\section{A Statistical Theory}

To be able to interpolate and even extrapolate the topographic information, we must have a model. The classic square-section prisms mentioned earlier are a typical example. A more powerful approach is to draw upon the theory of stochastic processes [Priestley, 1981; Vanmarcke, 1983]: we assume the elevation function $h(\mathbf{x}), \mathbf{x} \in \mathbf{R}^{2}$ is a sample of a stationary random process. Therefore it is associated with an autocovariance function

$$
R_{h}(\mathrm{x})=\operatorname{cov}[h(\mathrm{y}), h(\mathrm{y}+\mathrm{x})]
$$

or equivalently its Fourier transform, the power spectral density (PSD)

$$
S_{h}(\mathbf{k})=\int_{\mathbb{R}^{2}} R_{h}(\mathbf{x}) \exp (-2 \pi \mathrm{ik} \cdot \mathbf{x}) d^{2} \mathbf{k}
$$

We may estimate these functions from the survey data and other miscellaneous survey lines. Furthermore, we shall assume the process is isotropic; that is, the correlation does not depend on the direction of $\mathbf{x}$ in (B1), only its length; this means that the PSD, $S_{h}$, is a function of $|\mathbf{k}|$, which we write simply as $k$. Evidence for this symmetry will be presented later. We use our knowledge of the correlation of the topography from place to place to make estimates of the gravitational attraction from our samples of the topography.

In the following we shall assume that the topographic process $h$ has zero mean. We calculate the vertical gravitational attraction experienced by an observer at $x_{0}$ at a height $z_{0}$ above the mean level caused by the undulations $h$ of the basement-ice interface. If the density jump at the interface is $\Delta p$, the gravity anomaly is approximately

$$
\Delta g\left(\mathbf{x}_{0}\right)=\int_{\mathbf{R}^{2}} \frac{G \Delta p z_{0} h(\mathrm{~s})}{\left(z_{0}^{2}+\left|\mathrm{x}_{0}-\mathrm{s}\right|^{2}\right)^{3 / 2}} d^{2} \mathrm{~s}
$$

or

$$
\Delta g=\psi * h
$$

where $*$ means convolution. The approximation is based upon condensing the matter in columns of height $h$ into a thin surface layer at the mean level; the error incurred is negligible compared with other uncertainties for measurements at the ice surface where $z_{0} \approx 2000 \mathrm{~m}$, but not for sites deep in the borehole. Therefore, since we know the topography accurately close to the borehole, we shall use the approximate equation (B3) only for matter outside a disc of radius $a$; we replace (B3) by

$$
\Delta g_{>}=\psi_{>} * h
$$

where

$$
\psi_{>}(\mathbf{x})= \begin{cases}0 & |\mathbf{x}| \leq a \\ \frac{G \Delta p z_{0}}{\left(z_{0}^{2}+|\mathbf{x}|^{2}\right)^{3 / 2}} & |\mathbf{x}|>a\end{cases}
$$

If $h$ is considered to be a stochastic process, then so is $\Delta g$, and we may compute its PSD: it follows from (B4) by wellknown theory that

$$
S_{\Delta \xi_{>}}(\mathbf{k})=\left|\hat{\psi}_{>}(\mathbf{k})\right|^{2} S_{h}(\mathbf{k})
$$

where $\hat{\psi}_{>}$is the Fourier transform of $\psi_{>}$. We see from its definition (B5) that $\psi_{>}$is symmetric about the origin, and so its 
Fourier transform is given by

$$
\begin{aligned}
\hat{\psi}_{>}(\mathbf{k}) & =\int_{0}^{\infty} 2 \pi r d r J_{0}(2 \pi k r) \psi_{>}(r \hat{\mathbf{x}}) \\
& =2 \pi G \Delta \rho z_{0} \int_{a}^{\infty} \frac{J_{0}(2 \pi k r) r d r}{\left(z_{0}^{2}+r^{2}\right)^{3 / 2}}
\end{aligned}
$$

This integral is evaluated numerically.

The total variance of a random process is the integral over all wave numbers of its PSD. Thus we can predict the expected signal from terrain beyond the radius $a$ at the various observation sites in the borehole. One more refinement is needed, however: all observations are referred to the measurement made at the wellhead. We must find not just $\Delta g>$ but

$$
D g_{>}=\Delta g_{>}-\Delta g{ }^{0}
$$

where the second term is the gravity anomaly at the top of the borehole. From now on, (B4) will be replaced by

$$
D g_{>}=D \psi_{>} * h
$$

where $D \psi>$ is the difference between $\psi>$ evaluated for $z=z_{0}$, the gravimeter height in the borehole, and $z=z_{\text {top }}$, the height of the wellhead above the mean basement level. Integrating over the PSD of $D g_{>}$, we have

$$
\operatorname{var}\left[D g_{>}\right]=\int_{\mathbb{R}^{2}} d^{2} \mathbf{k}|\hat{D}(\mathbf{k})|^{2} S_{k}(\mathbf{k})
$$

where $D \hat{\psi}_{>}$is the Fourier transform of $D \psi_{>}$. Anticipating the results of the next section, where we estimate the PSD of the interface topography, let us calculate from (B7) the rms expected contributions for the borehole gravimeter sites. In Table B1 the mean level of the basement was taken to be $2004 \mathrm{~m}$ below the wellhead, the density contrast used was $1780 \mathrm{~kg} / \mathrm{m}^{3}$, and the model power spectrum was substituted into (B7), which was then integrated numerically. The anomalous non-Newtonian forces are anticipated to be of the order of $1 \mathrm{mGal}$ over the entire length of the borehole. This calculation shows that a terrain correction based solely on the 5-km-radius local radar survey would have an unacceptably large uncertainty due to unaccounted for topography beyond the disk. We also see that exact correction out to $25 \mathrm{~km}$ would be adequate and to $50 \mathrm{~km}$ excellent.

We consider next the question of how to make the best use of the relatively poor topographic data available in the distance range $5-50 \mathrm{~km}$. Our approach is identical to the method of least squares collocation, widely used in geodesy [Moritz, 1966]. We sketch the derivation from standard statistical principles. We are given a finite number of observations of the basement elevation $h_{1}, h_{2}, h_{3}, \ldots, h_{N}$. Because the relationship (B2) between the

TABLE B1. Effect of Distant Topography

\begin{tabular}{cccc}
\hline $\begin{array}{c}\text { Gravimeter } \\
\text { depth } \\
(\mathrm{m})\end{array}$ & $\begin{array}{c}a=5 \mathrm{~km} \\
\mathrm{~ms} D g> \\
(\mathrm{mGal})\end{array}$ & $\begin{array}{c}a=25 \mathrm{~km} \\
\mathrm{~ms} D g> \\
\text { (mGal) }\end{array}$ & $\begin{array}{c}a=50 \mathrm{~km} \\
\mathrm{~ms} D g_{>} \\
(\mathrm{mGal})\end{array}$ \\
\hline 213.2 & 0.326 & 0.0322 & 0.0092 \\
396.1 & 0.621 & 0.0599 & 0.0171 \\
579.0 & 0.928 & 0.0876 & 0.0251 \\
761.8 & 1.248 & 0.1154 & 0.0330 \\
944.6 & 1.578 & 0.1432 & 0.0409 \\
1309.4 & 2.266 & 0.1988 & 0.0568 \\
1491.2 & 2.620 & 0.2266 & 0.0647 \\
1673.2 & 2.980 & 0.2544 & 0.0726 \\
\hline
\end{tabular}

interface height $h$ and the correction is linear (accurately enough for our purposes), it is natural to write an approximation for (B6) as a weighted sum of the data:

$$
\Delta g_{>}\left(\mathbf{x}_{0}\right) \approx \sum_{n=1}^{N} w_{n} h_{n}
$$

For any given set of weights $w_{n}$ the error of this representation is

$$
\begin{aligned}
\varepsilon & =\sum_{n=1}^{N} w_{n} h_{n}-\psi_{>} * h \\
& =\left[\sum_{n=1}^{N} w_{n} \delta\left(\mathbf{x}_{n}\right)-\psi_{>}\right] * h
\end{aligned}
$$

where the basement heights were sampled at vector positions $x_{n}$ relative to $\mathbf{x}_{0}$. Our objective is make the overall error as small as we can by choosing the weights $w_{n}$ properly.

Since $\varepsilon$ is merely the convolution of $h$ with a filter function, it too is a stochastic process. We calculate its total variance by the integral of the PSD:

$$
\operatorname{var}[\varepsilon]=\int_{\mathbb{R}^{2}}\left|\sum_{n=1}^{N} w_{n} \exp \left(-2 \pi \mathrm{ik}-\mathbf{x}_{n}\right)-D \hat{\psi}_{>}\right|^{2} S_{h}(\mathbf{k}) d^{2} \mathbf{k}
$$

This integral can be interpreted as the square of the norm of a Hilbert space with inner product

$$
(f, g)=\int_{\mathbb{R}^{2}} f(\mathbf{k}) g(\mathbf{k})^{*} S_{h}(\mathbf{k}) d^{2} \mathbf{k}
$$

Then (B9) shows that the variance minimization is equivalent to the problem of approximating the function $D \hat{\psi}$, with an element in a subspace of functions, a classic problem in optimization theory [Luenberger, 1969]. Before minimizing this functional we should recognize another contribution to the uncertainty of the correction: the values of $h_{n}$ themselves are subject to quite large imprecisions $( \pm 30 \mathrm{~m})$. We can assume these errors are independent of each other and of the variance associated with the stochastic system; the total variance becomes

$$
\operatorname{var}[\varepsilon]=\sum_{n=1}^{N} w_{n}^{2} \sigma_{n}^{2}+\left\|\sum_{n=1}^{N} w_{n} e_{n}-D \hat{\psi}_{>}\right\|^{2}
$$

where $e_{n}$ is an abbreviation for the exponential function $\exp \left(-2 \pi i \mathbf{k} \cdot \mathbf{x}_{n}\right)$, and $\sigma_{n}^{2}$ is the variance of the observation $h_{n}$. To find the best weights, we differentiate with respect to $w_{n}$ and find the condition for stationarity; the following set of linear equations results:

$$
\sum_{n=1}^{N}\left[\left(e_{m}, e_{n}\right)+\sigma_{n}^{2} \delta_{m n}\right] w_{n}=\left(e_{m}, D \hat{\psi}_{>}\right), m=1,2, \ldots, N
$$

Because of the circular symmetry of all the functions, the inner product integrals can be simplified:

$$
\begin{aligned}
\left(e_{m}, e_{n}\right) & =\int_{0}^{\infty} 2 \pi J_{0}\left(2 \pi k\left|\mathbf{x}_{m}-\mathbf{x}_{n}\right|\right) S_{h}(k) k d k \\
\left(e_{m}, D \hat{\Psi}_{>}\right) & =\int_{0}^{\infty} 2 \pi J_{0}\left(2 \pi k\left|\mathbf{x}_{m}\right|\right) D \hat{\psi}_{>}(k) S_{h}(k) k d k
\end{aligned}
$$

The functions $S_{h}$ and $D \hat{\psi}_{>}$depend only on $k=|\mathbf{k}|$, and so we have used $k$ as their argument in these expressions; no confusion should result from this inconsistency. Notice that (B11) can also be written simply as

$$
\left(e_{m}, e_{n}\right)=R_{h}\left(\mathbf{x}_{m}-\mathbf{x}_{n}\right)
$$


Equation (B10) must be solved for $w_{n}$, and then the minimum total variance can be found from

$$
V_{\min }=\left\|D \hat{\psi}_{>}\right\|^{2}-\sum_{n=1}^{N} w_{n}\left(e_{n}, D \hat{\psi}_{>}\right)
$$

where

$$
\left\|D \hat{\psi}_{>}\right\|^{2}=\int_{0}^{\infty} 2 \pi D \hat{\psi}_{>}(k)^{2} S_{h}(k) k d k
$$

which is an alternative form of (B7). We use (B12) to give the mns uncertainty. When the weights $w_{n}$ are substituted into (B8), they give our estimate of $D g_{>}$.

\section{The PSD of the Interface Topography}

A visual inspection of the contour maps made from the local and the regional surveys fails to reveal any strong lineaments or other regularities. This suggests that the representation as an isotropic, homogeneous process is plausible. It is easiest to estimate a PSD for profiles, as it is well known [e.g., Parker et al., 1987] that the profile spectrum, $S_{P h}\left(k_{x}\right)$, is related to the full two-dimensional PSD by

$$
S_{P h}\left(k_{x}\right)=\int_{-\infty}^{\infty} S_{h}\left(k_{x}, k_{y}\right) d k_{y}
$$

from which it follows [Bracewell, 1965] that the isotropic PSD function is the inverse Abel transform of the profile PSD:

$$
S_{h}(k)=S_{h}(|\mathbf{k}|)=-\frac{1}{\pi} \int_{k}^{\infty} \frac{d S_{P h}}{d k_{x}} \frac{d k_{x}}{\left(k_{x}^{2}-k^{2}\right)^{1 / 2}}
$$

We computed the power spectral density for the high wave number regime from the local survey. This was done by averaging periodogram estimates of tapered [Priestley, 1981] profiles, first along north-south tracks, then east-west ones. The similarity of the two profile PSD curves (see Figure B1) supports the isotropic model. The same kind of analysis was carried out on the gridded regional data provided by $\mathrm{C}$. Tscherning (private communication, 1987). Again there is reasonable similarity between spectra estimated on north-south and on east-west lines. When we compare the spectra derived from the local and regional surveys, we find the agreement between the two spectra is somewhat disappointing: the regional survey gives a much

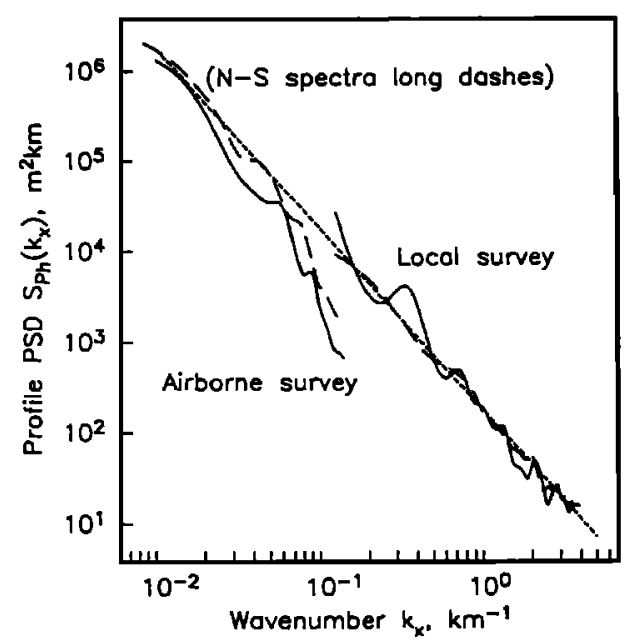

Fig. Bl. A comparison of power spectral densities of the sub-ice topography. smaller amplitude at $k_{x}=0.1 \mathrm{~km}^{-1}$ than does the local survey. We attribute the small values of the spectrum in the regional survey to the smoothing used to put the original aircraft track data onto a regular grid. With this in mind we fit the combination of spectra with a simple straight line, shown dashed in Figure B1. The equation of the line is

$$
S_{P h}\left(k_{x}\right)=A / k_{x}^{2}
$$

The value of $A$ is $180 \mathrm{~m}^{2} / \mathrm{km}$ or $0.18 \mathrm{~m}$. The behavior of this kind of model is unsatisfactory at the low wave number end of the spectrum because of its infinite variance. We may tame the singularity by introducing a characteristic wave number $\kappa$ below which the spectrum levels off:

$$
S_{P h}\left(k_{x}\right)=A /\left(\kappa^{2}+k_{x}^{2}\right)
$$

The corresponding two-dimensional PSD is

$$
S_{h}(k)=\frac{1 / 2 A}{\left(\kappa^{2}+k^{2}\right)^{3 / 2}}
$$

and the autocovariance function of this model topography is exponential:

$$
R_{h}(\mathbf{x})=(A \pi / \kappa) \exp (-2 \pi \kappa|\mathbf{x}|)
$$

Clearly, we cannot decide upon a reasonable value for $\kappa$ using the local data. Therefore we digitized some additional very long single lines taken by aircraft in the southern half of Greenland. Within a $100-\mathrm{km}$ radius of Dye 3 the basement topography appears to be moderately homogeneous, with a standard deviation of about $200 \mathrm{~m}$. Beyond this we find mountain ranges or we encounter the coast; in the mountainous region the ms undulation of the basement rises to about $600 \mathrm{~m}$. Obviously, we cannot insist on a stationary model for the largest scales, but the influence of the topography at the extreme ranges is modest (see Table B1). Therefore our model power spectrum is adjusted to give the proper variance for the local region; this implies $\mathrm{K}=0.014 \mathrm{~km}^{-1}$. We repeated most of the calculations with $\mathrm{K}=0.0014 \mathrm{~km}^{-1}$, which corresponds to an rms topography of $600 \mathrm{~m}$, the value seen in the most rugged areas, and discovered that, fortunately, the results are almost completely insensitive to the choice of $\mathrm{K}$ in this range.

\section{APPENDIX C: EFFECTS OF DEEP MASSES}

\section{Long Wavelength Anomalies}

The anomalous vertical gravity gradient, remaining after the local topography has been removed, might arise from the presence of large but distant density anomalies, perhaps deeply buried. The presence of such bodies can be detected with a large-scale surface gravity survey, data widely available in North America and Europe; such a survey has not been performed in the interior of Greenland because of the expense and unusual difficulties in performing local terrain correction at each measurement site (the local terrain is hidden under several thousand meters of ice). The best we can do is to calculate the very large scale gravity anomalies from a high-degree spherical harmonic model of the Earth's gravitational potential. R. Rapp of the Department of Geodetic Science and Surveying at Ohio State University generously provided us with his degree 360 models OSU86E and OSU86F. It might be anticipated that we should be able to calculate the effect of features with wavelengths down to 1 degree or about $100 \mathrm{~km}$; we shall see, however, that this is not in fact possible. 
The field models supply a large but finite number of dimensionless coefficients $c_{l m}$ in the infinite expansion of a gravitational potential

$$
T(r, \theta, \phi)=-\frac{G M_{e}}{r} \sum_{l=2}^{\infty}\left[\frac{a}{r}\right]^{l} \sum_{m=-l}^{l} c_{l m} Y_{l}^{m}(\theta, \phi)
$$

The potential is the difference between that observed and the one from a reference ellipsoidal body with the same mass as the Earth, rotating at the same rate and in hydrostatic equilibrium; it therefore gives us what we require - the gravitational field of anomalous density distributions. In (C1) the $Y_{l}^{m}$ are fully normalized, complex harmonics, $G$ is Newton's gravitational constant, $M_{e}$ is the Earth's mass, and $a$ its equatorial radius. We use the physicist's sign convention, with $g=-\nabla U$, where $U$ is the total geopotential. We introduce a nonstandard gravity anomaly, $\Delta g$, defined as the perturbation in $g=|g|$ at a fixed point in space. This is not the usual free-air anomaly, which accounts for the distortion of the geoid by the anomalous masses. Our anomaly is

$$
\Delta g=+\frac{\partial T}{\partial r}
$$

The difference between true vertical and the radial direction are generally negligible for our purposes and will be ignored. The vertical deviation of the geoid, a standard equipotential surface, from the reference ellipsoid is called $N$. Approximately,

$$
N=-T / g
$$

where both $T$ and $g$ are measured on the reference ellipsoid. Since $g$ is constant on the ellipsoid to better than 1 part in 100 , geoid undulations quite accurately mirror the variations of the potential, on the surface of the ellipsoid.

To get some idea of the behavior of the geopotential we plot a spherical harmonic 'power spectrum' derived from OSU86E in Figure $\mathrm{Cl}$, defined by

$$
S_{l}=a^{2} \sum_{m}\left|c_{l m}\right|^{2}
$$

From (C3) we can see that the normalization by $a^{2}$ makes $S_{l}$ the power spectrum of $N$. When $l>110$, we find $S_{l}=6.1 \times 10^{6} l^{-4.33} \mathrm{~m}^{2}$. Also plotted is the model spectrum corresponding to Kaula's Rule of Thumb [Kaula, 1968], which states $\left|c_{l m}\right|=C l^{-2}$.

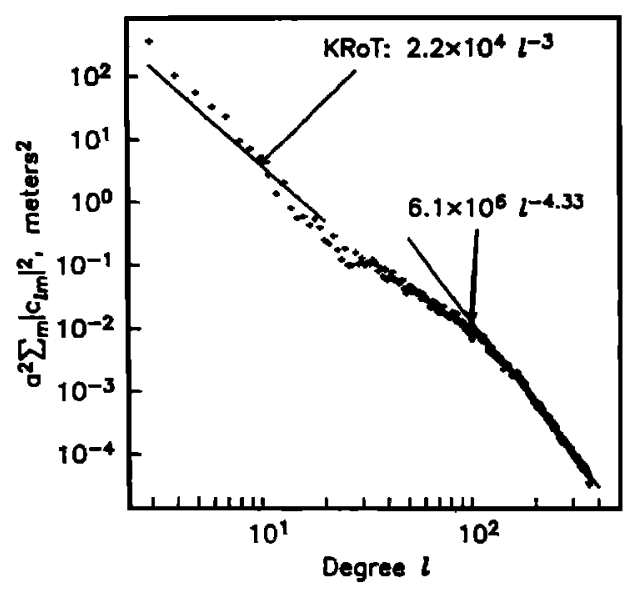

Fig. C1. The spectrum of geoid undulations.
Our interest is in $\partial \Delta g / \partial r$, the anomalous free-air gradient. Recall this is not the $r$ gradient of the free-air gravity anomaly. From (C2) we see we must differentiate $T$ twice; it is traditional to differentiate inside the sum in (C1):

$$
\frac{\partial \Delta g}{\partial r}=-\frac{G M_{e}}{r^{3}} \sum_{l=0}^{\infty}(l+1)(l+2)\left[\frac{a}{r}\right]^{l} \sum_{m=-l}^{l} c_{l m} Y_{l}^{m}(\theta, \phi)
$$

Because the Earth is oblate, points on the geoid lie inside the sphere $r=a$; there is no guarantee an exterior expansion like (C1) is convergent within this sphere. Therefore we shall set $r=a$ for our evaluations; when the scale of the features is several hundred kilometers, this causes a negligible perturbation to the numerical results since the shift in position is only about $20 \mathrm{~km}$. Even so, differentiating inside the sum is valid for an infinite series only if it converges uniformly with respect to the variable in an interval containing the point of evaluation, and since $r=a$, this condition is far from trivial given the behavior evident in Figure $\mathrm{Cl}$. Whether or not (C5) converges at $r=a$, we know $\partial \Delta g / \partial r$ exists (that is, it is finite) because every solution to Laplace's equation is analytic away from the boundaries. Inserting the ground location of the wellhead at the Dye 3 borehole $\left(65.186^{\circ} \mathrm{N},-43.8197^{\circ} \mathrm{E}\right)$, we evaluate $(\mathrm{C5})$ and $(\mathrm{Cl})$ scaled to give $N$ as in (C3). Instead of presenting the sum of all the terms to $l=360$ we plot the much more informative partial sums for successive degrees in Figure C2. The figure apparently shows that the geoid undulation $N$ has converged to a reasonable precision after only $l=15$; in fact, we find $N=+45.7 \mathrm{~m}$. The conventional free-air gravity anomaly is also shown; it too converges quite nicely to $29.2 \mathrm{mGal}$. In contrast, the partial sums for $\partial \Delta g / \partial r$ have not settled down at all even after all the terms available have been taken. Therefore it is most unlikely that the sum to $l=360$ has any significance for our experiment. What can be done to improve the situation?

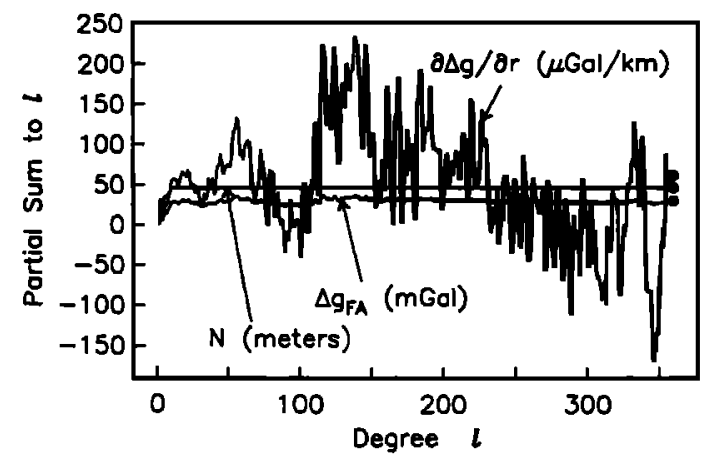

Fig. C2. Convergence of geoid height, $N$, free air gravity, $\Delta g_{\mathrm{FA}}$, and vertical gravity gradient, $\partial \Delta g / \partial r$, at Dye 3 .

It is helpful to make the following identification. Since $\nabla^{2} T=0$, expanding $\nabla^{2}$ in spherical polar coordinates, we have on $r=a$

$$
\frac{\partial \Delta g}{\partial r}=-\frac{2 \Delta g}{a}-\frac{\nabla_{s}^{2} T}{a^{2}}
$$

where $\nabla_{s}^{2}$ is the surface Laplacian on the sphere. The first term on the right is generally quite small (about $20 \mu \mathrm{Gal} / \mathrm{km}$ at Dye 3). Neglecting this term and using (C3) and treating $g$ as a constant, we have approximately

$$
\frac{\partial \Delta g}{\partial r}=\left(g / a^{2}\right) \nabla_{s}^{2} N
$$


(For marine experiments, precise geoid height measurements can be obtained by radar altimetry, and so (C6), or its more accurate predecessor, solves the problem of estimating $\partial \Delta g / \partial r$ directly.) Let us return to (C1). Truncation of the infinite, slowly convergent series gives rise to the Gibbs' phenomenon, since spherical harmonics are the Fourier series of the sphere. The wiggliness is accentuated when the second derivative surface is needed as in (C6). To minimize these effects, one could smooth the function $N$ before differentiating. This is equivalent to applying a taper to the coefficients $c_{l m}$ before submitting them to (C5). We chose a Gaussian weight series, with $e$-folding at $l=200$, with the convergence results shown in Figure C3. This has the effect of calculating $\partial \Delta g / \partial r$ for density anomalies with scales greater than or equal to $2 \pi a / 200$ or $200 \mathrm{~km}$. We find that $\partial \Delta g / \partial r=68 \mu \mathrm{Gal} / \mathrm{km}$. The result is completely different from that obtained simply by stopping (C5) at $l=200$, namely, $19 \mu \mathrm{Gal} / \mathrm{km}$, but it is much more reliable. (The skeptical reader should apply the technique to calculate the first derivative of the function whose Fourier series is $\sum \sin n x / n$ at $x=\pi / 4$.) We are applying a primitive form of the classical theory of convergence factors [Walker, 1988].

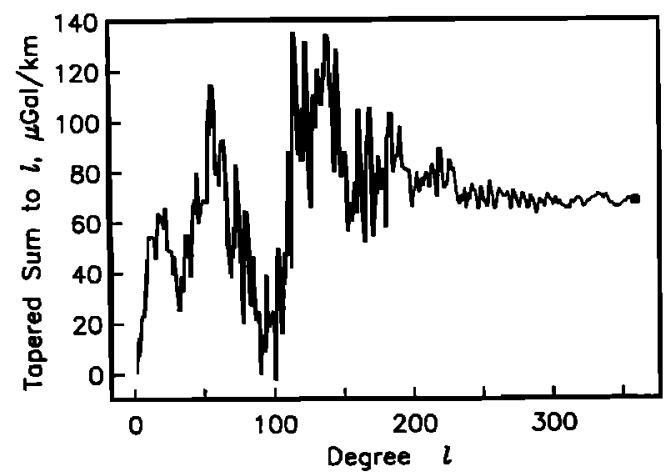

Fig. C3. Convergence of tapered gravity gradient series at Dye 3 .

The question remains, What are the contributions to $\partial \Delta g / \partial r$ from density anomalies with scales smaller than $200 \mathrm{~km}$ ? We have a gravity survey with a diameter of $30 \mathrm{~km}$ and a radar basement map good enough to correct for terrain effects on that scale. Therefore the question becomes one of estimating the possible contributions in the gap from 30 to $200 \mathrm{~km}$, or $l=200$ to 1300 . To obtain a rough estimate, we construct a model for the coefficients $c_{l m}$. Note how the line for $\partial \Delta \mathrm{g} / \partial r$ in Figure C2 resembles a random walk, the sum of a series of identical uncorrelated disturbances. Also, suppose the trend in Figure $\mathrm{Cl}$ beginning at $l=110$ continues out to $l=1300$. This suggests that when $l>110$ the coefficients $c_{l m}$ can be regarded as the realization of a zero-mean random process; but the variance depends only on $l$ and the members will be assumed to be uncorrelated. In fact, from the power law trend we calculate

$$
\operatorname{var}\left[c_{l m}\right]=\frac{\alpha l^{-4.33}}{2 l+1}
$$

where $\alpha=1.5 \times 10^{-7}$. Of course, we cannot calculate the actual value of the anomalous free-air gradient from this model, but we can find a rough estimate of its magnitude by asking how far the random walk is likely to have wandered between $l=200$ and $l=1300$. We calculate the expected value of the squared distance:

$$
R^{2}=\mathrm{E}\left[\frac{G M_{e}}{a^{3}} \sum_{l=200}^{1300}(l+1)(l+2) \sum_{m=-l}^{l} c_{l m} Y_{l}^{m}(\theta, \phi)\right]^{2}
$$

Using the presumed independence of the $c_{l m}$ together with (C7), we find after some algebra that $(\mathrm{C} 8)$ reduces to

$$
\begin{aligned}
R^{2} & =\frac{G^{2} M_{e}^{2} \alpha}{4 \pi a^{6}} \sum_{l=200}^{1300}(l+1)^{2}(l+2)^{2} l^{-4.33} \\
& =\frac{G^{2} M_{e}^{2} \alpha}{4 \pi a^{6}} \sum_{l=200}^{1300} l^{-0.33}=\frac{g^{2} \alpha}{4 \pi a^{2}} \int_{200}^{1300} l^{-0.33} d l
\end{aligned}
$$

Evaluating and taking the square root we have an rms value of $192 \mu \mathrm{Gal} / \mathrm{km}$.

In conclusion, we may say that there is only a small contribution $(68 \mu \mathrm{Gal} / \mathrm{km})$ to the free-air gravity gradient from very long wavelength density anomalies in the Earth (scale $>200 \mathrm{~km}$ ). Assuming a uniform spectral behavior, we can show that the additional contributions from disturbances with scales down to $30 \mathrm{~km}$ can be expected to be considerably larger, with a predicted $\mathrm{mns}$ value of $192 \mu \mathrm{Gal} / \mathrm{km}$. This figure can be considered to be the uncertainty in the long wavelength anomaly. It is still much smaller than the observed borehole gradient. From this we conclude that the cause of the gradient is not distant mass anomalies.

Acknowledgments. We are indebted to scores of individuals who helped with both the field phase and analysis phase of this experiment The Polar Ice Coring Office played a key role in logistics and operations; efforts by K. Kuivenin, R. Kelty, C. Rohn, K. Swanson, and D. Brummond are appreciated. The Dye 3 personnel, B. Bach in particular, were all helpful. Important equipment and/or data were supplied by $M$. Ethridge, W. E. Strange, M. Grunthal, and W. V. Mast (National Geodetic Survey); A. Cogbil (Los Alamos National Lab), K. Jezek (NASA) W. Kerr (Kerr Measurements), R. Rapp (Ohio State Universiry), J. Sumner (University of Arizona), C. Tscheming (The Geodetic Institute of Denmark), and R. Ware (UNAVCO). N. Gundestrup (University of Copenhagen) supplied the ice-borehole reamer and kindly allowed us to modify it on the site. We are grateful to G. Beutler, B. Perin, and K. Larson for their efforts in reducing the GPS data. The scientific and technical advice of G. Backus, C. Bentley, A. Chave, C. Glover, J. Hildebrand, F. Spiess, R. Vickers, and J. H. Zumberge were most helpful. We thank the Heckla Mining Co. for providing access to the Consolidated Silver mine as well as assistance during the wireline calibration. This research was supported by the National Science Foundation, Los Alamos National Laboratory under the auspices of the Department of Energy, Amoco Production Co., the Institute for Geophysics and Planetary Physics, the Air Force Geophysics Laboratory, and the University of Texas at Dallas. Finally, we acknowledge the efforts of those who helped coordinate funding: D. Eckhardt, C. F. Keller, Jr., W. F. Miller, Jr., C. W. Myers, and H. B. Zimmerman.

\section{REFERENCES}

Adelberger, E. G., C. W. Stubbs, W. F. Rogers, F. J. Raab, B. R. Heckel, J. H. Gundlach, H. E. Swanson, and R. Watanabe, New constraints on composition-dependent interaction weaker than gravity, Phys. Rev. Lett., 59, 849-852, 1987.

Airy, G. B., Account of pendulum experiments undertaken in the Harton colliery for the purpose of determining the mean density of the earth, Philos. Trans. R. Soc. London., 146, 297-342, 1856.

Ander, M. E., and S. P. Huestis, Gravity ideal bodies, Geophysics, 52, 1265-1278, 1987.

Ander, M. E., M. A. Zumberge, T. Lautzenhiser, R. L. Parker, C. L. V. Aiken, M. R. Gorman, M. M. Nieto, A. P. R. Cooper, J. F. Ferguson, E. Fisher, G. A. McMechan, G. Sasagawa, J. M. Stevenson, G. Backus, A. D. Chave, J. Greer, P. Hammer, B. L. Hansen, J. A. Hildebrand, J. R. Kelty, C. Sidles, and J. Wirtz, A test of Newton's 
inverse-square law in the Greenland ice cap, Phys. Rev. Lett., 62, 985-988, 1989.

Bartlett, D. F., and W. L. Tew, Possible effect of the local terrain on the Australian fifth force experiment, Phys. Rev. D, 40, 673, 1989.

Beutler, G., W. Gurtner, M. Rothacher, U. Wild, and E. Frei, in Global Positioning System: An Overview, Proc. IAG Symp. 102, edited by Y. Bock and N. Leppard, Springer-Verlag, New York, in press, 1990.

Boynton, P. E., C. Crosby, P. Ekstrom, and A. Szumilo, Search for an intermediate-range composition-dependent force, Phys. Rev. Lett., 59 , 1385-1389, 1987.

Bracewell, R., The Fourier Transform and Its Applications, 381 pp, McGraw-Hill, New York, 1965.

Briggs, I. C., Machine contouring using minimum curvature, Geopyhsics 39, 39-48, 1974.

Clotfelter, B. E., The Cavendish experiment as Cavendish knew it, Am. J. Phys., 55, 210-213, 1987.

Eckhardt, D. H., C. Jekeli, A. R. Lazarewicz, A. J. Romaides, and R. W. Sands, A tower gravity experiment: Evidence for non-Newtonian gravity, Phys. Rev. Lett., 60, 2567-2570, 1988.

Evans, S. and B. M. E. Smith, A radio echo equipment for depth sounding in polar ice sheets, J. Sci. Instrum., Ser. 2, 2, 131-136, 1969.

Fischbach, E., D. Sudarsky, A. Szafer, C. Talmadge, and S. H. Aronson, Reanalysis of the Eötvös experiment, Phys. Rev. Lett., 56, 3-6, 1986.

Fisher, E., G. A. McMechan, M. R. Gorman, A. P. R. Cooper, C. L. V. Aiken, M. E. Ander, and M. A. Zumberge, Determination of bedrock topography beneath the Greenland ice sheet by three-dimensional imaging of radar sounding data, J. Geophys. Res., 94, 2874-2882, 1989.

Fujii, Y., Dilaton and possible non-Newtonian gravity, Nature, 234, 5-7, 1971.

Gillies, G. T., The Newtonian gravitational constant, an index of measurements, Metrologia, 24 (Suppl.), 1-56, 1987.

Goldman, T., R. J. Hughes, and M. M. Nieto, Experimental evidence for quantum gravity?, Phys. Lett., 17IB, 217-222, 1986.

Gorman, M. R., and A. P. R. Cooper, A digital radio echo-sounding and navigation recording system, Ann. Galciol., 9, 81-84, 1987.

Gow, A. J., Relaxation of ice in deep drill cores from Antarctica, $J$. Geophys. Res., 76, 2533-2541, 1971.

Gudmandsen, P. E., and E. L. Christensen, Radioglaciology: Activities in the Period September 19-October 3, 1971, Rep. D141, Electromagn. Inst., Tech. Univ. of Den., Lyngby, 1972.

Gundestrup, N. S., and B. L. Hansen, Bore-hole survey at Dye 3, south Greenland, J. Glaciol., 30, 282-288, 1984.

Gundestrup, N. S., and S. J. Johnsen, A bantery powered, instrumented deep ice core drill for liquid filled holes, in Greenland Ice Core: Geophysics, Geochemistry, and the Environment, Geophys. Monogr. Ser. vol. 33, edited by C. C. Langway, Jr., H. Oeschger, and W. Dansgaard, pp. 19-22, AGU, Washington, D.C., 1985.

Hammer, C. U., H. B. Clausen, W. Dansgaard, A. Neftel, P. Kristinsdottir, and E. Johnson, Continuous impurity analysis along the Dye 3 deep core, in Greenland Ice Core: Geophysics, Geochemistry, and the Environment, Geophys. Monogr. Ser., vol. 33, edited by C. C Langway, Jr., H. Oeschger, and W. Dansgaard, pp, 90-94, AGU, Washington, D.C., 1985.

Herron, M. M., and C. C. Langway, Jr., Firn densification: an empirical model, J. Glaciol., 25, 373-385, 1980.

Hildebrand, J. A., A. D. Chave, F. N. Spiess, R. L. Parker, M. E. Ander, and $M$. A. Zumberge, The Newtonian gravitational constant - On the feasibility of an oceanic measurement, Eos. Trans. AGU, 69, 769, $779-780,1988$.

Hobbs, P. V., Ice Physics, 837 pp, Clarendon, Oxford, 1974.

Holding, S. C., F. D. Stacey, and G. J. Tuck, Gravity in mines - An investigation of Newton's law, Phys. Rev. D, 33, 3487-3494, 1986.

Jekeli, C., A. J. Romaides, and D. H. Eckhardt, Refined analyses of tower gravity experiment - A null result? (abstract), Eos, Trans. $A G U, 70,1058,1989$.

Jezek, K. C., E. A. Roeloffs, and L. L. Greischar, A geophysical survey of subglacial geology around the deep-drilling site at Dye 3, Greenland, in Greenland Ice Core: Geophysics, Geochemistry, and the Environment, Geophys. Monogr. Ser., vol. 33, edited by C. C. Langway, Jr. H. Oeschger, and W. Dansgaard, pp.105-110, AGU, Washington, D.C., 1985.

Kaula, W. M., An Introduction to Planetary Physics - The Terrestrial Planets, 490 pp, John Wiley, New York, 1968.

Langway, C. C., H. Oeschger, and W. Dansgaard, The Greenland ice sheet program in perspective, in Greenland Ice Core: Geophysics,
Geochemistry, and the Environment, Geophys. Monogr. Ser., edited by C. C. Langway, Jr. H. Oeschger, and W. Dansgaard, Pp. 1-8, AGU, Washington, D.C., 1985.

Luenberger, D. G., Optimization by Vector Space Methods, 319 pp, Johe Wiley, New York, 1969.

Luther, G. G., and W. R. Towler, Redeterminarion of the Newtonias gravitational constant, Phys. Rev. Lett., 48, 121-123, 1982.

Moritz, H., Methods for downward continuation of gravity, Ohio State Univ., Columbus Dept. of Geodetic Science Rep. 67, Ohio State University Research Foundation, 1966.

Nieto, M. M., R. J. Hughes, T. Goldman, M. E. Ander, C. L. V. Aiken G. A. McMechan, and J. F. Ferguson, Analysis of the Greenland icesheet experiment in terms of new gravitational forces, Phys. Lett. B, $228,448-452,1989$.

Overgaard, S., Radio Echo Sounding: GISP-1978, Field Rep. AR56 Electromagn. Inst., Tech. Univ of Den., Lyngby, 1978.

Overgaard, S., Radio Echo Sounding: GISP-1978, Field Rep. AR72, Electromagn. Inst., Tech. Univ of Den., Lyngby, 1979.

Overgaard, S., and N. S. Gundestrup, Bedrock topography of the Greenland ice sheet in the Dye 3 area, in Greenland Ice Core: Geophysics. Geochemistry, and the Environment, Geophys. Monogr. Ser., vol. 33, edited by C. C. Langway, Jr. H. Oeschger, and W. Dansgaard, pp. 49-56, AGU, Washington, D.C., 1985.

Parker, R. L., Best bounds on density and depth from gravity data, Geophysics, 39, 644-649, 1974.

Parker, R. L., The theory of ideal bodies for gravity interpretation, Geophys. J. R. Astron. Soc., 42, 315-334, 1975.

Parker, R. L., and M. A. Zumberge, An analysis of geophysical experiments to test Newton's law of gravity, Nature, 342, 29-32, 1989.

Parker, R. L., L. Shure, and J. A. Hildebrand, The application of inverse theory to seamount magnetism, Rev. Geophys, 25, 17-40, 1987.

Pontikis, C., Determination de la constante de gravitation par la methode de resonance, C. R. Acad. Sci., Ser. B, 274, 1972.

Priestley, M. B., Spectral Analysis and Time Series, 653 pp, Acadenic, San Diego, Calif., 1981.

Raynaud, D., and B. Lebel, Total gas content and surface elevation of polar ice sheets, Nature, 281, 289-291, 1979.

Sasagawa, G. S., M. A. Zumberge, J. M. Stevenson, T. Lautzenhiser, J. Wirtz, and M. E. Ander, 1987 southeastem Alaska gravity calibration range: Absolute and relative gravity measurements, J. Geophys. Res., $94,7661-7666,1989$.

Shoji, H., and C. C. Langway, Jr., Mechanical properties of fresh ice core from Dye 3, Greenland, in Greenland Ice Core: Geophysics, Geochemistry, and the Environment, Geophys. Monogr. Ser., vol. 33. edited by C. C. Langway, Jr., H. Oeschger, and W. Dansgaard, pp. 39-48, AGU, Washington, D.C., 1985.

Sondergaard, F., Radioglaciology: Surface Soundings near Dye 3, Rep. $D 258$. Electromagn. Inst., Tech. Univ of Den., Lyngby, 1975.

Stacey, F. D., and G. J. Tuck, Geophysical evidence for non-Newtonian gravity, Nature, 292, 230-232, 1981.

Stacey, F. D., G. J. Tuck, S. C. Holding, A. R. Maher, and D. Morris, Constraint on the planetary scale value of the Newtonian gravitational constant from the gravity profile within a mine, Phys. Rev. D, 23, 1683-1692, 1981.

Stacey, F. D., G. J. Tuck, G. I. Moore, S. C. Holding, B. D. Goodwin, and R. Zhou, Geophysics and the law of gravity, Rev. Mod. Phys., 59, 157-174, 1987.

Stubbs, C. W., E. G. Adelberger, F. J. Raab, J. H. Gundlach, B. R. Heckel, K. D. McMurry, H. E. Swanson, and R. Watanabe, Search for an intermediate-range interaction, Phys. Rev. Lett., 58, 1070-1073, 1987.

Thieberger, P., Search for a substance dependent force with a new differential accelerometer, Phys. Rev. Lett., 58, 1066-1069, 1987.

Thomas, J., P. Kasameyer, O. Fackler, D. Felske, R. Harris, J. Kammeraad, M. Millet, and M. Mugge, Testing the inverse-square law of gravity on a 465-m tower, Phys. Rev. Lett., 63, 1902-1905, 1989.

Vanmarcke, E., Random Fields, Analysis and Synthesis, 382 pp. MTT Press, Cambridge, Mass., 1983.

Walker, J. S., Fourier Analysis, Oxford University Press, New York, 1988.

Wen, J., and G. A. McMechan, Application of three-dimensional kinematic imaging to analysis of seismic reflection data from the Nevada Test Site, Bull. Seismol. Soc. Am., 74, 2187-2199, 1984.

Wen, J., and G. A. McMechan, Three-dimensional kinematic migration in variable velocity media, Geophys. Prospect., 35, 250-266, 1987. 
Windley, B. F., The Evolving Continents, 2nd Ed., 399 pp, John Wiley, New York, 1984.

C. L. V. Aiken, J. F. Ferguson, E. Fisher, and G. A. McMecham, Center for Lithospheric Studies, University of Texas at Dallas, Richardson, TX 75083-0688.

M. E. Ander, and M. M. Nieto, Los Alamos National Laboratory, University of California, Los Alamos, NM 87545.

A. P. R. Cooper, and M. R. Gorman, Scott Polar Research Institute, University of Cambridge, Cambridge, United Kingdom.

J. Greer, UNAVCO, CIRES, University of Colorado, Boulder, CO 80309.
P. Hammer, R. L. Parker, G. S. Sasagawa, J. M. Stevenson, and M. A. Zumberge, Institute of Geophysics and Planetary Physics, Scripps Institution of Oceanography, University of Califomia, San Diego, La Jolla, CA 92093-0225.

B. L. Hansen, University of Nebraska, Lincoln, NE 68588-0640.

T. V. Lautzenhiser, and T. Wirz, AMOCO Production Company, Tulsa, OK 74102.
(Received December 12, 1989; revised February 27, 1990, accepted April 1, 1990.)

